\title{
Knowledge in the Face of Conspiracy Conditionals*
}

\author{
Ben Holguín
}

April 2020

\begin{abstract}
A plausible principle about the felicitous use of indicative conditionals says that there is something strange about asserting an indicative conditional when you know whether its antecedent is true. But in most contexts there is nothing strange at all about asserting indicative conditionals like 'If Oswald didn't shoot Kennedy, then someone else did'. This paper argues that the only compelling explanation of these facts requires the resources of contextualism about knowledge.
\end{abstract}

\section{Introduction}

As I will understand the view, moderate invariantism about knowledge is the combination of two theses: (i) the moderate part: that we are generally in a position to know what is believed on the basis of perception, memory, and testimony; and (ii) the invariantist part: that if $\ulcorner\mathrm{S}$ knows that $\mathrm{p}\urcorner$ is true in one context of use, it is true in every context of use. ${ }^{1}$ For the purposes of this paper we may abstract away from discussion of the moderate invariantist's preferred theory of the conditions under which perception, memory, and testimony suffice for knowledge. What matters are the specific knowledge attributions the moderate invariantist wants to deliver-i.e., the kinds of case by case judgments her theory is designed to predict. And on that matter I take it to be uncontroversial that, for many adults $\mathrm{S}$, we can speak truly in claiming that $\mathrm{S}$ knows the propositions expressed by the following sentences: ${ }^{2}$

$\left(\mathbf{P}_{1}\right) \mathrm{S}$ has hands.

*Forthcoming in Linguistics and Philosophy. Thanks to Kyle Blumberg, Cian Dorr, Jeremy Goodman, Harvey Lederman, Jake Nebel, Jim Pryor, Rose Ryan-Flinn, Trevor Teitel, and Jake Zuehl for helpful discussion of previous drafts. Thanks also to three anonymous reviewers for significantly improving the paper with their detailed and substantive comments.

${ }^{1}$ Given the potential context-sensitivity of the expressions $\ulcorner S\urcorner$ and $\ulcorner\mathrm{p}\urcorner$, this condition isn’t quite right. More accurate would be something like: If $\ulcorner\mathrm{S}$ knows that $\mathrm{p}\urcorner$ is true in one context $c$, then it is true in every context $c^{\prime}$ that assigns the same semantic value to $\ulcorner\mathrm{S}\urcorner$ and $\ulcorner\mathrm{p}\urcorner$ as $c$ assigns them. But I will stick with the simpler construal in the main text for the sake of readability.

${ }^{2}$ The point would be cleaner but more cumbersome to state if $\left(\mathrm{P}_{1}\right)-\left(\mathrm{P}_{3}\right)$ were made tenseless. 
$\left(\mathbf{P}_{2}\right)$ Donald Trump is the president of the United States.

$\left(\mathbf{P}_{3}\right)$ Oswald shot Kennedy.

This paper argues that if a certain independently plausible principle about the felicitous use of indicative conditionals is true, then there is at least one context $c$ (in fact many) in which for each of the above sentences $\left(\mathrm{P}_{1}\right)-\left(\mathrm{P}_{3}\right)$, the proposition expressed by $\left\ulcorner\mathrm{S}\right.$ knows that $\left.\left(\mathrm{P}_{n}\right)\right\urcorner$ is false in $c$. By extension, then, if the principle is true, then moderate invariantism about knowledge is false.

What's the principle? Put roughly, it's that there is something generally strange about asserting an indicative conditional $\ulcorner$ If $\mathrm{p}, \mathrm{q}\urcorner$ when you know whether $\mathrm{p}$. Thus, since conditionals like

(1) If Oswald didn't shoot Kennedy, then someone else did.

seem unproblematically assertable in a variety of ordinary contexts—or so I will argue-then contrary to the predictions of moderate invariantism, it appears that there are ordinary contexts in which $\ulcorner S$ doesn't know whether Oswald shot Kennedy $\urcorner$ expresses a true proposition.

It will then be argued that given the considerations motivating the principle, the best explanation of the existence of contexts in which it appears that (e.g.) $\ulcorner$ S doesn't know that Oswald shot Kennedy $\urcorner$ expresses a true proposition is that 'knows' is context-sensitive. Views that give an alternative diagnosis of these facts-say that the appearance of (1)'s felicity is misleading, or that it is part of the semantics of 'knows' that those who are inclined to find (1) felicitous context-invariantly fail to know that Oswald shot Kennedy-are not plausible. Thus, the best account of our intuitive judgments about the felicitous use of indicative conditionals requires a contextualist theory of knowledge.

\section{IGNORANCE}

We begin with IGNORANCE, the principle that connects our judgments about the felicitous uses of the indicative conditional to facts about what is known. Put roughly, the principle is that whenever one knows whether $\mathrm{p}$, there will generally be something strange about asserting an indicative conditional whose antecedent is p. Why "generally" rather than, say, always? Because as we will discuss in detail in $\S 3$, there is a distinction between canonical and non-canonical uses of the indicative conditional, and the strangeness arises only on the canonical uses. But more on that later.

With that caveat in the background, here is a precise statement of the core principle:

IGNORANCE In every context $c$ : if $\ulcorner S$ knows whether $\mathrm{p}\urcorner$ is true in $c$, then $\ulcorner$ It is inappropriate for $\mathrm{S}$ to assert the indicative conditional 'If $\mathrm{p}, \mathrm{q}$ ' in the canonical way is true in $c$. 
Here we use '(in)appropriate' in a quasi-technical sense, whereby an assertion is appropriate iff the content of the assertion is neither false nor presuppositionally defective, nor carries any problematic implicatures. Consequently, readers should understand the domain of contexts over which IGNORANCE quantifies as implicitly restricted to those in which 'appropriate' receives its technical interpretation. I should also point out that on our quasi-technical reading of 'appropriate', it is possible for an assertion to be inappropriate even when none of the relevant interlocutors is in a position to know that it is. For example, this can happen when the content of the assertion is false but believed to be true. When the gap between appropriateness and the appearance of appropriateness might matter, we will be careful to distinguish the two. ${ }^{3}$

The motivating thought behind IGNORANCE is the combination of the general principle that one's choice of words can impart information about one's epistemic state, plus the idea that the main purpose of the indicative conditional is for reasoning and talking about propositions whose truth-value is unknown. The idea really is an intuitive one. If you've settled whether $\mathrm{p}$, you shouldn’t be asserting things like $\ulcorner$ If $\mathrm{p}, \mathrm{q}$ ? . Instead, you either should be asserting $\mathrm{q}$

${ }^{3}$ Some readers may wonder why the consequent of IGNORANCE is stated meta-linguistically. (If you don't wonder about this, I suggest you skip this footnote.) The reason is this. Assuming 'knows' is context-sensitive, there is a question of how to interpret slogans like 「If S knows whether p, then S shouldn't assert 'If p, q' $\urcorner$. They can either be interpreted as universal generalizations over all contexts, or they can be interpreted as claims about specific contexts. If they're interpreted as universal generalizations over all contexts, then the principle we're working with is:

In every context $c$ : $\ulcorner$ If $S$ knows whether $\mathrm{p}$, then $\mathrm{S}$ shouldn't assert 'If $\mathrm{p}, \mathrm{q}\urcorner$ expresses a truth in $c$.

Now suppose $\ulcorner\mathrm{S}$ shouldn't assert 'If $\mathrm{p}, \mathrm{q}\urcorner\urcorner$ is context-insensitive, and thus that it either expresses a truth in every context or a falsehood in every context. Given that $\ulcorner$ If $S$ knows whether $\mathrm{p}$, then $\mathrm{S}$ shouldn't assert 'If $\mathrm{p}$, q' $\urcorner$ expresses a truth in every context (by hypothesis), it follows that if there is $a$ context in which $\ulcorner S$ knows whether $\mathrm{p}\urcorner$ expresses a truth, then in every context $\ulcorner\mathrm{S}$ shouldn't assert 'If $\mathrm{p}$, q' $\urcorner$ must express a truth. But this is exactly what we're going to want to deny, for we're going to see evidence that the appropriateness of the assertion of a indicative conditionals varies across contexts. So if we want to think of the slogan underlying IGNORANCE as a universal generalization over all contexts, we need both its antecedent and consequent to be relativized to contexts. Hence the doubly meta-linguistic statement of the principle.

Of course there remains the question of why we're treating the slogan underlying IGNORANCE as a universal generalization over all contexts. Why not instead think the true principle is something like:?

If $\ulcorner\mathrm{S}$ knows whether $\mathrm{p}\urcorner$ expresses a truth in S's context, then S shouldn't assert 'If $\mathrm{p}, \mathrm{q}$ '.

I lack the space to explain fully why I find this implementation inadequate, but the basic worry is this (see also Worsnip 2017 for similar discussion). In making the facts about the appropriateness of the assertion of S's assertion of indicative conditional depend invariantly on features of S's context, we predict that speeches like the following should be acceptable:

(2) ? Although S knows whether $\mathrm{p}$ (and we don't), she was being perfectly cooperative in answering 'If $\mathrm{p}$, q' when we asked her whether q.

For suppose S is in a context in which she would speak truly in asserting 'I don't know whether p', but that we are in a context in which we would speak truly in asserting ' $S$ knows perfectly well whether p' (maybe $S$ in the grip of a skeptical puzzle and we aren't). Then for all the present version of IGNORANCE is concerned, (2) should be fine. But as we will see shortly, there is good reason to think that speeches like (2) are context-invariantly problematic. So I think the only contextualist-friendly way of interpreting IGNORANCE is as a principle that establishes a penumbral connection between the truth of sentences about knowledge and the truth of sentences about whether certain indicative conditionals are appropriate to assert. As far as I can see, the only principle capable of doing this is IGNORANCE in its doubly meta-linguistic form. (Thanks to an anonymous reviewer for pressing me to say more about this issue.) 
(when you know that p), or-if determined to assert a conditional—you should be asserting a counterfactual $\ulcorner$ If it were that p, it would be that. .. $\urcorner$ (when you know that $\neg$ p). That is the case for IGNORANCE stripped to its core. More can be said in the principle's favor-and that is what the rest of this section will do-but the arguments are in some sense all variations on the same theme.

However, before getting to these arguments, it will be helpful to have on the table some principles about the relationship between knowledge and assertion. Here are three closely related ones that will appear at various points in later discussion: ${ }^{4}$

KSA In every context $c$ : If $\ulcorner S$ knows that $\mathrm{p}\urcorner$ is true in $c$, then $\ulcorner$ It is epistemically appropriate for $\mathrm{S}$ to assert that $\mathrm{p}\urcorner$ is true in $c$.

KNA In every context $c$ : If $\ulcorner$ It is epistemically appropriate for $S$ to assert that $\mathrm{p}\urcorner$ is true in $c$, then $\ulcorner\mathrm{S}$ knows that $\mathrm{p}\urcorner$ is true in $c$.

—and their conjunction:

KA In every context $c$ : $\ulcorner$ It is epistemically appropriate for $S$ to assert that $\mathrm{p}\urcorner$ is true in $c$ iff $\ulcorner S$ knows that $\mathrm{p}\urcorner$ is true in $c$.

In words: KSA says that knowledge is (epistemically) sufficient for assertion; KNA says that knowledge is (epistemically) necessary for assertion; and KA is the conjunction of KSA and KNA. The 'epistemically' qualifier is meant to control for cases in which an assertion of $\mathrm{p}$ would be problematic for reasons that go beyond the speaker's evidential grounds for $\mathrm{p}$. These are cases in which the assertion of $\mathrm{p}$ is impolite or otherwise harmful, as well as cases in which the assertion is pragmatically problematic - say because it is too weak, irrelevant, misleading, etc. I will not defend any of these principles about knowledge and assertion here, though I will make some suggestive remarks in their favor later in the paper (§6). Some of the arguments for IGNORANCE will make use of KSA, others will make use of KNA, and some will make use of neither. But having the principles on hand will make all of this easier to track.

With these points in place, the main argument in favor of IGNORANCE is simple: indicative conditionals with antecedents whose truth values are taken to be known tend to sound quite strange. Here is an example. Suppose your (otherwise normal) friend Jane comes up to you and says:

(3) ? If I had a bagel for breakfast this morning, then I went out for brunch with Jim.

If you are like me, you will find such an utterance puzzling. The thoughts that suggest themselves are: (i) that Jane has forgotten what she ate for breakfast; or (ii) that Jane is trying to engage you in some kind of unpleasant puzzle about her daily activities. The same is true of:

\footnotetext{
${ }^{4}$ For some arguments in favor of there being a connection between knowledge and assertion along the lines of these norms (though not necessarily in their exact form), see (e.g.) Unger (1975, ch. 6); Williamson (2000, ch. 11); DeRose (2002); Benton (2016); Turri (2016). See also Worsnip (2017) and the citations therein for a sense of the larger debate around knowledge accounts of assertion, with particular attention to its relationship to epistemic contextualism.
} 
(4) ? If I didn't have a bagel for breakfast this morning, then I ate cereal at home.

Supposing you know Jane isn't the kind of person to speak in roundabout ways about what she ate for breakfast-i.e., that (ii) isn't happening-you might be inclined to respond along the lines of:

(5) What do you mean if you had [didn't have] a bagel for breakfast this morning? Do you not remember what you ate for breakfast?

The fact that (3) and (4) seem strange and that (5) seems like an appropriate response admits of a straightforward explanation: when someone utters an indicative conditional $\ulcorner$ If $\mathrm{p}$, $\mathrm{q}\urcorner$, we typically infer that that person does not know whether . $^{5}$ Since you would expect Jane to know whether she ate a bagel for breakfast, her utterance of an indicative like (3) or (4) is jarring. This is what IGNORANCE is designed to reflect.

Before continuing on to other evidence in favor of IGNORANCE it is worth emphasizing two points about this example. First, notice how much the conditionals improve if the breakfast under discussion isn't this morning's, but one from a few weeks ago:

(3*) If I had a bagel for breakfast two Saturdays ago, then I went out for brunch with Jim.

(4*) If I didn't have a bagel for breakfast two Saturdays ago, then I ate cereal at home.

Why the improvement? Because obviously there is no general presumption that people know what they ate for breakfast weeks ago. IGNORANCE correctly has no complaint about an assertion of either $(3 *)$ or $\left(4^{*}\right)$.

Second, the fact that (3) and (4) seem strange is evidence of more than just the general claim that the assertability of indicative conditionals has something to do with knowledge. It is evidence that the assertability of indicative conditionals has something to do with the speaker's knowledge. In the imagined circumstances of Jane's utterances, her interlocutors do not know whether she had a bagel for breakfast. (Nor are they presupposing one way or the other, we may assume.) Still, there is something strange about Jane's assertion. So the principle about the felicitous use of indicative conditionals cannot merely be that one shouldn't assert $\ulcorner$ If $\mathrm{p}, \mathrm{q}\urcorner$ when one's interlocutor's know that $(\neg)$ p. What matters is whether the speaker knows it. ${ }^{6}$

Further evidence for IGNORANCE comes from the oddity of speeches of the form $\ulcorner$ p, but if $\neg \mathrm{p}, \mathrm{q}\urcorner:$

(6) ?? Lexie is playing viola right now. But if she isn't playing viola right now she's sleeping.

(7) ?? It rained every day last week. But if it didn't rain every day last week then there was a good day for a picnic.

\footnotetext{
${ }^{5}$ Given a contextualist account of 'knows', this way of making the point is somewhat sloppy with use and mention. But the basic point is just that when someone asserts a conditional like (3) or (4), a natural thought to go through your head will be along the lines of 'Does that person not know whether they had a bagel for breakfast this morning?'.

${ }^{6}$ We will revisit this point in some detail in $\S 6$.
} 
I'm not sure whether these speeches ought to be classified as incoherent or merely very strange, but I'm going to take it as a datum that there is something definitely not right about them. ${ }^{7}$ Given KNA—the principle that says knowledge is (epistemically) necessary for assertion-IGNORANCE provides a simple explanation of the felt oddity of (6)-(7). And that is: (i) if you are taken to be in a position to assert that $\mathrm{p}$, then you will be taken to know that p; (ii) given IGNORANCE, if you are taken to be in a position to assert that $\ulcorner$ If $\neg p$, $q\urcorner$, then you will be taken not to know that p; thus (iii), in asserting that $\ulcorner p$ but if $\neg p, q\urcorner$ you represent yourself as both knowing that $\mathrm{p}$ and not knowing that $\mathrm{p}$. Hence why (6)-(7) seem bizarre.

Lastly, it is worth making a general point about why we should expect IGNORANCE to be true, at least when we restrict attention to the sorts of conversational settings those working in the tradition of, e.g., Grice (1975) and Gazdar (1979) take themselves to be theorizing about. Here the considerations separate somewhat neatly between cases of indicatives with antecedent that are known to be true and cases of indicatives with antecedents that are known to be false.

Start with indicatives whose antecedents are known to be true. You know that p, and are considering whether to assert $\ulcorner$ If $\mathrm{p}, \mathrm{q}\urcorner$. There are three possibilities: either you know that $\mathrm{q}$, you know that $\neg \mathrm{q}$, or you neither know q nor know $\neg q$. No matter which obtains, there will be something peculiar about an assertion of $\ulcorner$ If $\mathrm{p}$, $\mathrm{q}\urcorner$. If you know that $\mathrm{q}$, then an assertion of $\ulcorner$ If $\mathrm{p}$, $\mathrm{q}\urcorner$ is problematically weak. Why assert the conditional when you could have just asserted $\mathrm{q}$ (or $\ulcorner p$ and $q\urcorner)$ ? It would be strange much in the way it is strange to say 'Some of my students failed' when you know that all of your students failed. ${ }^{8}$ If instead you know that $\neg \mathrm{q}$, then the problem with an assertion of $\ulcorner$ If $p, q\urcorner$ is even simpler: bracketing exotic putative counterexamples to modus ponens, the conditional is straightforwardly false, or is at least the kind of thing in which you should have approximately zero confidence. Finally, if you do not know whether q, then for all you know the material conditional $\mathrm{p} \supset \mathrm{q}$ expresses a falsehood. Given the standard assumption that the indicative conditional entails the material conditional, it follows from KNA that the indicative is unassertable. So no matter your epistemic state with respect to q, you shouldn't assert $\ulcorner$ If $\mathrm{p}, \mathrm{q}\urcorner$ when you know that $\mathrm{p}$.

With respect to cases in which the antecedent is known to be false, I appeal to the idea that these are circumstances in which you ought to be asserting a counterfactual conditional $\ulcorner$ If it were that $\mathrm{p}$, it would be that... $\urcorner$ rather than an indicative one. ${ }^{9}$ Support for this idea, at least

${ }^{7}$ Though see the discussion of so-called 'echoing' and 'concessive' uses of the indicative conditional in §3. Also see Dorst (2019a) for some evidence to the contrary.

${ }^{8} \mathrm{~A}$ similar line of reasoning suggests that it should be generally impermissible to assert $\ulcorner p$ or $q\urcorner$ when either disjunct is known, as well as $\ulcorner$ If $\mathrm{p}, \mathrm{q}\urcorner$ when the consequent $\mathrm{q}$ is known. I think these generalizations are basically as good as the one IGNORANCE is meant to capture, but the class of exception cases is messier for them than it is for IGNORANCE.

${ }^{9}$ A note about terminology: I distinguish indicative conditionals from counterfactual conditionals wholly in terms of their semantic properties, rather than (e.g.) their syntactic properties. Putting things as roughly as our purposes call for: an indicative conditional is a conditional whose semantics concerns what is happening at a contextually determined set of epistemic possibilities, while a counterfactual conditional is a conditional whose semantics concerns what is happening at a contextually determined set of (sometimes epistemically impossible) metaphysical possibilities. Nothing in this distinction rules out the existence of conditionals with indicative marking (e.g., $\ulcorner$ If p, q $\urcorner$ ) whose semantics is counterfactual, and likewise conditionals with subjunctive marking (e.g., $\ulcorner$ If it were/had been that p, it would be/would have been that $\mathrm{q}\urcorner$ ) whose semantics is indicative. See, e.g., von Fintel (1999); Khoo (2015) and the 
in some form or another, is widespread in the literature on conditionals. ${ }^{10}$ Indeed, many believe it is a presupposition of the indicative that its antecedent is an epistemic possibility. I will thus take this half of IGNORANCE to be relatively uncontroversial.

That is the case for IGNORANCE. Setting aside the quality of the arguments just presented in its favor, the principle seems to me something of a platitude about the standard use of indicative conditionals. I have yet to encounter an alternative theory of the sorts of reactions we have to speeches like (3)-(7) in the literature, and I imagine that is because much of the work on conditionals takes something like IGNORANCE for granted. That there is a tension between moderate invariantism about knowledge and IGNORANCE is thus of interest in its own right, even for those who would give up the latter before the former.

\section{Non-canonical uses of the indicative conditional}

Before giving the argument against moderate invariantism from IGNORANCE, it is important that we get clear on the nature of the qualifier about canonical uses of the indicative conditional. This section will present a brief taxonomy of non-canonical uses, and then say a bit about what unifies the conversational circumstances in which one tends to find them.

The most straightforward statement of the difference between canonical and non-canonical uses of the indicative conditional is this: when used canonically, an indicative conditional $\ulcorner$ If $p$, $\mathrm{q}\urcorner$ is a device for reasoning about and expressing connections between propositions that are open in the relevant context. All other uses are non-canonical. What does it mean for a proposition to be open in a context? Well, that's a matter that can (and will in §6) be disputed, but the natural thought is that a proposition's being open is, unsurprisingly, a matter of neither it nor its negation being known. On this way of understanding the canonical/non-canonical distinction, canonical uses of $\ulcorner$ If $\mathrm{p}, \mathrm{q}\urcorner$ are those in which the speaker does not know whether $\mathrm{p}$, while non-canonical uses are those when the speaker does know whether $\mathrm{p}$.

Now obviously this way of characterizing the distinction isn't very helpful at the present stage of the dialectic. Our aim is to use IGNORANCE to leverage intuitive judgments about indicative conditionals into arguments against non-contextualist theories of knowledge. But if a conditional can only be used in the canonical way if its antecedent is unknown, then IGNORANCE expresses a triviality.

With that concern in mind, I believe the easiest way to get a theory-neutral grip on the canonical/non-canonical distinction is though examples. Taking a rough stab at a reasonably comprehensive taxonomy, here are the (non-canonical) uses of the indicative conditional that I believe call for the distinction in question:

First there are echoing uses, e.g.: ${ }^{11}$

citations therein for further discussion.

${ }^{10}$ See, e.g., Stalnaker (1975), von Fintel (1999), Gillies (2010), Leahy (2011), Khoo (2015).

${ }^{11}$ I get the 'echoing' label from Dorr \& Hawthorne (2013, pp. 890-91). 
(8) If Pete's report is accurate, then Peggy is working at home. But we know Peggy never works from home, so Pete's report must be inaccurate.

(9) If Dave is here, Roger is at home. Dave is here, so Roger is at home.

Echoing uses tend to occur in circumstances in which the speaker is rehearsing (echoing) her evidence for various propositions she takes herself to have settled: in this case either the negation of the conditional's antecedent, as in (8), or the conditional's consequent, as in (9). More generally, echoing uses occur in what one might think of as "dialectical" contexts-situations in which one is trying to give an argument for a known conclusion, or in which one is trying to reason one's way from known premises to a (soon to be) known conclusion. Consequently, a simple test for identifying an echoing use of $\ulcorner$ If $p, q\urcorner$ in the wild is to ask whether in the same context a followup assertion of $\ulcorner\mathrm{p}$; so $\mathrm{q}\urcorner$ or $\ulcorner\neg \mathrm{q}$; so $\neg \mathrm{p}\urcorner$ would be appropriate; if it would be then you are probably dealing with an echoing use of $\ulcorner$ If $\mathrm{p}, \mathrm{q}\urcorner \cdot{ }^{12}$

Second there are Dutchman uses, e.g.:

(10) If Jeremy goes to the gym twenty hours a week, then I'm a Dutchman.

(11) If Emily can afford to quit her job, then I'm a monkey's uncle.

Dutchman uses are essentially just echoing uses with flair. They are used to communicate the negations of their antecedents.

And third, there are Concessive uses, e.g.:

(12) I know I cannot afford this timeshare. But even if I'm wrong about that, I still don't want to buy it.

(13) I am not lying about where I live. And even if I am, you're not going to get a different answer from me.

Concessive uses of $\ulcorner$ If $\mathrm{p}, \mathrm{q}\urcorner$ tend to occur in circumstances in which the speaker has settled that $\neg$ p and q, but knows that it is unlikely that her audience will take her to know whether $\neg$ p. In light of this the speaker must settle for a "backup" position, q. In these circumstances a speech like $\ulcorner\neg \mathrm{p}$; but even if $\mathrm{p}, \mathrm{q}\urcorner$ can seem perfectly natural. Consequently, a simple test for identifying a concessive use of $\ulcorner$ If $p, q\urcorner$ in the wild is to ask whether the use is occurring in a conversational context in which the speaker can expect her interlocutors to take her to know the things she asserts; if and only if the speaker can't expect to be trusted to know whether $\mathrm{p}$ if she were to assert $\mathrm{p}$ are you likely dealing with a concessive use of $\ulcorner$ If $\mathrm{p}, \mathrm{q}\urcorner$.

${ }^{12}$ As an anonymous reviewer points out, one who knows that $\neg$ p might want to assert the indicative conditional $\ulcorner$ If p, $\mathrm{q}\urcorner$ as a way of indicating that if one were to come to believe $\mathrm{p}$, one would also believe q. But one needn't be in a context in which it would be appropriate to assert $\ulcorner\neg q$; so $\neg \mathrm{p}\urcorner$ to do this. The aforementioned test thus only provides a sufficient condition for a conditional's being used in an echoic manner. 
Three quick observations about this taxonomy. First, as concerns the purposes of this paper, it is basically comprehensive. ${ }^{13}$ Second, it should be clear that none of these uses typically implicates that the speaker is ignorant of the truth value of the conditional's antecedent. In fact it is plausible that the opposite is implicated-i.e., that the speaker knows whether the antecedent is true. Third and most importantly, setting aside complaints about which uses of the conditional deserve the honorific 'canonical', there is an obvious difference between how the conditional is used in each of these cases and how it is used in the natural contexts associated with (3)-(7). One doesn't need a theory of the difference to be able to see it, and it should not go unappreciated that these various non-canonical uses have special labels.

Those points aside, what seems to me to be in common to the various non-canonical uses of the indicative conditional is that they all arise in circumstances in which the usual pressure to assert the strongest propositions relevant to the topic of conversation has been superseded by other communicative pressures. In the circumstances in which echoing (and Dutchman) uses are natural, the primary concern is not with sharing one's views on the topic, but with making explicit one's evidence for one's views on the topic. And in the circumstances in which concessive uses are natural, again the primary concern is not with sharing one's views on the topic, but with sharing the views that one expects one's uncooperative interlocutors will actually accept. By contrast, when one is in the kind of conversation where speakers are expected to just tell one another their views about the topic under discussion, one needn't worry about rehearsing inferential connections or hedging.

The natural thought, then, is that canonical uses of the indicative conditional arise in conversational circumstances in which it is expected that the participants assert what they can about the topic under discussion in a manner that meets an appropriate balance between informative-

\footnotetext{
${ }^{13}$ There are two other categories of conditionals whose uses are typically non-canonical, but whose discussion I omit from the main text given their failure to pose any clear problem for IGNORANCE: biscuit conditionals and donkey conditionals. Examples of biscuit conditionals include:

(14) There are biscuits on the sideboard if you want some.

(15) If you're interested James is playing at the Roadhouse tonight.

It should be clear that biscuit conditionals are unlike ordinary indicative conditionals, at least on the latter's standard uses. But regardless of whether or not they are canonical, they are not counterexamples to IGNORANCE. It is just as strange to assert a biscuit when one knows whether its antecedent is true as it is to assert an ordinary indicative when one knows whether its antecedent is true. (See, e.g., DeRose \& Grandy (1999) and Predelli (2009) for further discussion of biscuits.) Examples of donkey conditionals include:

(16) If a farmer owns a donkey, he beats it.

(17) If a cat has a hat, it wears it.

Mysteries abound with donkey conditionals—see, e.g., (King \& Lewis, 2017) for an introduction. I will not pay much attention to them here, as it is not obvious they even count as indicative conditionals in the sense I am interested in (see footnote 9 above). But even if they are genuine indicatives, then as far I can tell they are just echoing conditionals, and so what goes for those goes for these. But even if that's wrong, it should be clear that the conditionals of interest to this paper (to be introduced in §4) are relevantly dissimilar to conditionals like (16) and (17).
} 
ness and brevity. These are the sorts of conversational contexts theorists like Grice (1975) and Gazdar (1979) are trying to model the dynamics of. Whenever one is in a position to impart information to one's interlocutors and the question of whether q is relevant to the topic of conversation, one's assertion of 「If $\mathrm{p}, \mathrm{q}\urcorner$ will implicate that one doesn't know whether $\mathrm{p}$. If one knew that $\mathrm{p}$, then one would have been doing more to further the purposes of the conversation to assert $\mathrm{q}$; if one knew that $\neg$ p, then one would have done more to further the purposes of the conversation by asserting $\neg \mathrm{p}$ or a counterfactual conditional. Having asserted neither $\mathrm{q}$ nor $\neg$ p nor a counterfactual conditional, one can expect one's listeners to infer that one doesn't know whether p. Conversational contexts shaped by other goals are certainly possible (perhaps even quite common), but the uses of the indicative conditional they give rise to are nonetheless non-canonical. ${ }^{14}$

I conclude that the distinction between canonical and non-canonical uses is both natural and recognizable enough to leave the theoretical interest of IGNORANCE unscathed. For what IGNORANCE tells us is that if $S$ 's assertion of $\ulcorner$ If $\mathrm{p}, \mathrm{q}\urcorner$ is appropriate in a context, then either it occurred in conversational circumstances shaped by non-standard communicative pressures, or by the lights of the context $\ulcorner\mathrm{S}$ knows whether $\mathrm{p}\urcorner$ expresses a falsehood.

\section{The argument against moderate invariantism}

Having made the case for IGNORANCE in $\S 2$ and clarified the canonical/non-canonical distinction in $\S 3$, we can now turn to the argument against moderate invariantism about knowledge.

Recall that central to moderate invariantism about knowledge is the thesis that for many adults $\mathrm{S}$, it is context-invariantly true that $\mathrm{S}$ knows the following propositions:

$\left(\mathbf{P}_{1}\right) \mathrm{S}$ has hands.

$\left(\mathbf{P}_{2}\right)$ Donald Trump is the president of the United States.

$\left(\mathbf{P}_{3}\right)$ Oswald shot Kennedy.

With that in mind, let us say that an indicative conditional $\ulcorner$ If $\mathrm{p}, \mathrm{q}\urcorner$ is a conspiracy conditional just in case its antecedent expresses one of the various propositions (or the negations thereof) the moderate invariantist takes many people to context-invariantly know.

The colorful label is due to the paradigm case of such a conditional, which, thanks to Adams (1970), also happens to be a (philosophical) paradigm case of the indicative conditional:

\footnotetext{
${ }^{14}$ I should note that it would work just as well for our purposes if the primary conversational norm were "Assert the strongest relevant thing you know to be true and can expect your audience to believe you know to be true". In that case concessive uses of the indicative conditional would plausibly count as canonical, as their use would be responsive to the norm's second conjunct. But dialectically speaking this would just be a reshuffling of labels. As we will see in $\S 5$, the uses of indicative conditionals that are of central interest to this paper are not invariably concessive uses, and so whether those uses count as canonical or non-canonical is irrelevant to the truth of IGNORANCE (and, by extension, the truth of invariatism about knowledge).
} 
(1) If Oswald didn't shoot Kennedy, then someone else did.

The reason for (1)'s fame is that it makes for an excellent case study in the semantic differences between indicative and counterfactual conditionals-for compare (1), which is intuitively true, to its counterfactual analog (18), which is intuitively false:

(18) If Oswald hadn't shot Kennedy, someone else would have.

Somewhat surprisingly, however, (1)'s philosophical fame more or less ends here. The fact that its naturalness is in tension with a popular package of views on knowledge and the pragmatics of indicative conditionals has to my knowledge gone largely unnoticed. ${ }^{15}$ For again, if moderate invariantism and IGNORANCE are both true, then given that (1)'s antecedent is $\left(\mathrm{P}_{3}\right)$, its only appropriate use would have to be non-canonical uses. We will get into the prospects of such a line in more detail in $\S 5$, but for now it suffices to say that (1) seems like the kind of conditional that has appropriate canonical uses.

Conspiracy conditionals are by no means limited to conspiracies. Here are two others that seem fine out of the blue:

(19) If Trump is still president of the United States, then he hasn't had a fatal heart attack in the past few moments.

(20) If Trump is no longer the president of the United States, then it is surprising we haven't heard about that.

Likewise, suppose you're driving through the country side. In at least some contexts it would be perfectly normal to utter sentences like:

(21) If in a few hours the car breaks down, then we won't make it to our destination tonight.

(22) If these barns are more than a few days old, then it is unlikely we are driving through a movie set.

Given the assumption that we're typically in a position to know where we'll be in a few hours (at least absent good reason to expect that something will go wrong) and that barns we pass by on our way through the country have been around for more than a few days, we get further violations of IGNORANCE from (21)-(22).

The same can be said for standard cases of knowledge through testimony. If you read in the newspaper that Federer defeated Nadal in straight sets, then in at least some contexts it would be perfectly natural for you to express thoughts like:

(23) If Federer defeated Nadal in straight sets, then this report is accurate.

(24) If Federer didn't defeat Nadal in straight sets, then this report is inaccurate.

$\overline{15}$ The only exception I know of is Gillies (2004, p. 585), who mentions it once and then does not return to the issue. 
Finally, philosophical subject matters are a rich source of conspiracy conditionals:

(25) If you're in the good case, then you're not a handless BIV.

(26) If you don't know you have hands, then you're in the bad case.

(27) If nature is uniform, then induction is a reliable means of forming true beliefs.

(28) If the next time I drop this pen it floats in the air instead of falling, then either it's a very special pen or nature may not be so uniform after all.

But again, if we know anything by the moderate invariantist's lights, then we know that we know we have hands and that pens fall when they are dropped. ${ }^{16}$

Here is the upshot. We have reason to believe IGNORANCE is true and that each of the above conspiracy conditionals is assertable in the canonical way in at least some contexts. Moderate invariantism tells us that if $\ulcorner\mathrm{S}$ knows whether $\mathrm{p}\urcorner$ expresses a false proposition in one context, then it expresses a false proposition in every context. And IGNORANCE tells us that if S's canonical assertion of $\ulcorner$ If $\mathrm{p}, \mathrm{q}\urcorner$ is appropriate in one context, then the proposition expressed by $\ulcorner\mathrm{S}$ knows whether $\mathrm{p}\urcorner$ is false in that context. So IGNORANCE plus the facts about conspiracy conditionals look to eliminate large swaths of what the moderate invariantist takes us to know. That is the paper's core argument against moderate invariantism.

I see four ways the moderate invariantist could respond. First, accept IGNORANCE and argue that the appropriate uses of conspiracy conditionals are invariably non-canonical. Second, reject IGNORANCE in favor of a non-knowledge-centric theory of the pragmatics of indicative conditionals. Third, accept IGNORANCE, but give an error theory of our inclination to judge appropriate canonical uses of conspiracy conditionals. Or fourth, accept IGNORANCE and argue that speakers who sincerely assert conspiracy conditionals have simply lost their (context-invariant) knowledge of the truth or falsity of the antecedent. $\S \S 5-8$ address each of these replies in turn.

\section{Must conspiracy conditionals be non-canonical?}

Supposing the felicitous uses of conspiracy conditionals are always non-canonical, then IGNORANCE in combination with our judgments about those uses is no threat to the moderate invari-

\footnotetext{
${ }^{16}$ One philosophical case I find particularly sharp draws on some recent papers (cited below) on epistemic puzzles concerning unobserved tosses of fair coins. Suppose you know a fair coin is about to be flipped 1,000 times. Supposing the distribution of heads/tails in fact ends up being relatively normal, do you know prior to the coin's being flipped that it won't land heads all 1,000 times? There are persuasive arguments suggesting that the moderate invariantist must say 'Yes'-see, e.g., (Bacon, 2014, §1) and (Dorr et al. , 2014). Supposing these arguments are sound, it follows that these indicatives are conspiracy conditionals:

(29) a. If this fair coin lands heads 1,000 times in a row, then most onlookers will be quite confident that the coin is double-headed.

b. If this fair coin doesn't land heads 1,000 times in a row, then anyone who bet that it would will lose some money.
} 
antist's theory of knowledge. How might one defend this supposition? First, one could try to assimilate the relevant uses of conspiracy conditionals with the canonically non-canonical uses of the indicative conditional. That is to say, one could try and classify the natural uses of §4's conspiracy conditionals as kinds of echoing, Dutchman, or concessive uses. Alternatively, one could argue that conspiracy conditionals give rise to a sui generis kind of non-canonical use of the indicative conditional-a yet further exception to the general prohibition on asserting conditionals whose antecedents are known. I will argue that neither option is plausible.

\subsection{Conspiracy conditionals as canonically non-canonical}

Beginning with the first option, should we think that the natural uses of conspiracy conditionals are always echoing, Dutchman, or concessive uses?

The short answer is: No, we shouldn't. With only minimal amounts of reflection one should be able to see that ordinary uses of (e.g.)

(1) If Oswald didn't shoot Kennedy, then someone else did.

(24) If Federer didn't defeat Nadal in straight sets, then this report is inaccurate.

are not invariably echoing, Dutchman, or concessive uses. This is not to say they can't be. No one should deny that the same conditional can be used in all sorts of different ways. It's just that there are plenty of normal contexts in which, intuitively, one's intention in asserting a conditional like (1) or (24) is to tell one's interlocutors something informative about the subject of conversation, rather than to present evidence for what one knows or accommodate their distrustfulness.

Reflection on a case will help sharpen the point. Start with our paradigm conspiracy conditional:

(1) If Oswald didn't shoot Kennedy, then someone else did.

It goes without saying that (1) is not ordinarily used as a Dutchman. Must it be used in an echoic or concessive manner? The suggestion seems to me implausible. It implies that, invariably, the reason we assert (1) is not because we take it to be the strongest relevant thing we know about the question at hand; rather it's because we are trying to trace an inferential connection between the proposition that Oswald didn't shoot Kennedy and the proposition that someone other than Oswald shot Kennedy (when used in an echoic manner), or because we don't trust that our audience to believe the things we tell them about the JFK assassination (when used in a concessive manner).

With respect to echoic uses, it should be clear enough that we do not typically use (1) in the process of setting up a modus tollens argument:

If Oswald didn't shoot Kennedy, then someone else did. We know that someone else didn't shoot Kennedy. ?? Therefore, Oswald shot Kennedy. 
Such an argument accomplishes very little, to say the least. So (1)'s natural echoic uses are going to be more geared toward highlighting inferential connections. And although it is not difficult to imagine situations in which (1) would be used in this way-say to communicate that given what one knows, one would still believe that someone shot Kennedy even if one stopped believing that Oswald did-it is also not difficult to imagine contexts in which that kind of response would seem so unhelpful as to make it infelicitous. When a less knowledgeable person asks a more knowledgeable person for information on a topic, it is usually expected that the more knowledgable person will simply give the strongest relevant bit of information they can. They won't take the time to rehearse their evidence or highlight inferential connections unless they feel like they have to. If you ask me what I ate for breakfast, I'll say 'A bagel', not 'If I had a bagel it was a poppy seed bagel'. The latter might describe a genuine inferential connection. It might even serve the useful function of communicating that the only bagels I eat are poppy seed bagels. But I won't answer that way because doing so doesn't serve the purposes of the conversation. By a similar token, if I know you want to know about the circumstances of Kennedy's death, I will, if cooperative, just tell you what I take myself to know about the matter. Nothing more, nothing less. And as far as I can tell this is exactly what many people take themselves to be doing when they assert conditionals like (1). They're trying to share the strongest relevant bit information they have. So the felicitous uses of (1) are not invariably echoic in nature.

Similar considerations suggest that the felicitous uses of (1) are not invariably concessive in nature. A concessive use of (1) will be appropriate whenever one's interlocutors will not accept that you know Oswald shot Kennedy, but will accept that you know that someone did-circumstances which are not particularly difficult to imagine. But what is difficult to imagine is that these are the only circumstances in which an assertion of (1) is appropriate. In deciding to assert (1), one needn't think something like 'Well of course $I$ know that Oswald shot Kennedy, but since these people won't believe me I'll have to settle for "If Oswald didn't shoot Kennedy, then someone else did"'. No—pace the error theories to be discussed in §7—all goes perfectly well if one thinks 'I'm not sure whether Oswald shot Kennedy; but what I am sure of is that if Oswald didn't, someone else did' or 'Hmm - if Oswald didn't shoot Kennedy, then someone else did. I wonder who else might have shot him...' or what have you. The corresponding uses look to be straightforwardly canonical.

I will spare the reader similar analyses of the other examples discussed in $\S 4$. The analysis of the Oswald conspiracy conditionals should be enough to motivate this subsection's modest thesis: that the felicitous uses of conspiracy conditionals need not be (and often are not) among the familiar non-canonical uses of the indicative conditional. If they are deserving of some special non-canonical status, it must be of a sui generis kind. 


\subsection{Conspiracy conditionals as non-canonically non-canonical}

A proponent of this style of response has it that §3's taxonomy of non-canonical uses of the indicative conditional is incomplete: in addition to echoing, Dutchman, and concessive uses, there are also conspiratorial uses, or whatever you want to call them.

What's the argument in favor of expanding the domain of non-canonical uses of the indicative conditional to cover the natural uses of conspiracy conditionals? Well, presumably, it's that we want both IGNORANCE and moderate invariantism to be true, and we can't have that unless the natural uses of conspiracy conditionals form their own category of non-canonical use.

Aside from its dialectical awkwardness, I think there are strong reasons to be suspicious of this line of thinking. A unifying thread among the familiar kinds of non-canonical uses of the indicative conditional is that each has a pragmatic explanation for its existence. Echoing uses arise because sometimes it's important that speakers highlight inferential connections; Dutchman uses are just echoing uses with sarcasm; and concessive uses arise because sometimes speakers have to deal with interlocutors that are insufficiently trusting.

But the plausible explanations of the existence of conspiratorial uses cannot be like this. And that's because conspiracy conditionals may be used felicitously even in situations in which all the standard pragmatic pressures are present—pressures to assert the strongest thing you are in a position to assert, keep it brief, etc. As far as I can tell, then, the story that explains what makes the natural uses of conspiracy conditionals non-canonical will have to be an epistemic one. And the problem with such a story is that it is unclear what distinguishes (i) a view that says there are uses of the indicative conditional that are non-canonical because they arise in contexts with non-standard epistemic (rather than pragmatic) constraints on assertion from (ii) a view that says that there are uses of the indicative conditional that are counterexamples to IGNORANCE. One who accepts the former but denies the latter risks trivializing IGNORANCE by turning it into a principle that says that conditionals with known antecedents are assertable except when they're not.

If the moderate invariantist wants to stay in the business of taking our judgments about conspiracy conditionals at face value, then rather than invent ad hoc categories of non-canonical uses of the indicative conditional, she should simply take these conditionals to show that IGNORANCE is false. If it is non-negotiable that the proposition expressed by $\ulcorner S$ knows whether $\mathrm{p}\urcorner$ is true in every context, and if nonetheless there are contexts in which $S$ may appropriately assert $\ulcorner$ If $\mathrm{p}, \mathrm{q}\urcorner$ in exactly the same manner she may assert any other ordinary indicative conditional, then-contra IGNORANCE-there must be no general prohibition on asserting $\ulcorner$ If $\mathrm{p}, \mathrm{q}\urcorner$ in the canonical way when you know whether $\mathrm{p}$. 


\section{Replacing IGNORANCE?}

Perhaps the better strategy for the moderate invariantist is to reject IGNORANCE. One way of doing this is to deny that any generalization in the vicinity of IGNORANCE is correct. But I don't think this is a promising way of going. Such a view has no means of accounting for the empirical and theoretical considerations that compelled us to posit it in the first place, and should thus be held as a last resort.

So if the moderate invariantist wants to reject IGNORANCE, her best bet is to accept the following placeholder principle, but deny that 'is open' is to be understood along the lines of 'is compatible with what is known':

OPENNESS In every context $c$ : If $\ulcorner$ It isn't open for $S$ whether $\mathrm{p}\urcorner$ is true in $c$, then $\ulcorner$ It is inappropriate for $\mathrm{S}$ to assert 'If $\mathrm{p}, \mathrm{q}$ ' in the canonical way? is true in $c$.

This section will look at three kinds of theories of the being open relation, and assess whether they let OPENNESS give a satisfactory explanation of the considerations §2 raised in favor of IGNORANCE. They are: (i) theories that take the underlying epistemic relation to be invariantly something like belief, (ii) theories that take the underlying epistemic relation to be invariantly something like certainty, and (iii) theories that take the underlying relation to be defined in terms of the conversational common ground. In each case it will be argued that a knowledge-theoretic conception of OPENNESS is preferable to the alternative. I will then suggest that the failures of these alternatives makes a strong abductive case for IGNORANCE as the best implementation of OPENNESS.

\subsection{Against belief-theoretic conceptions of openness}

On a belief-theoretic conception of openness, a proposition $\mathrm{p}$ is open to $\mathrm{S}$ just in case $\mathrm{S}$ neither believes $p$ nor $\neg$. Understood in this way, OPENNESS says that whenever one believes that $p$, one should assert neither $\ulcorner$ If $\mathrm{p}, \mathrm{q}\urcorner$ nor $\ulcorner$ If $\neg \mathrm{p}, \mathrm{q}\urcorner \cdot{ }^{17}$

The problems with the belief-theoretic conception of OPENNESS are straightforward. First, on most standard views of knowledge, S's knowing that p entails S's believing that $\mathrm{p}$. So if contexts in which $S$ 's assertion of the conspiracy conditional $\ulcorner$ If $\mathrm{p}, \mathrm{q}\urcorner$ is appropriate are contexts in which $\mathrm{S}$ fails to believe either that $\mathrm{p}$ or that $\neg \mathrm{p}$, then on any of these accounts of knowledge, $\mathrm{S}$ will automatically fail to know whether $\mathrm{p}$ too.

Second, the view that $\mathrm{p}$ is open to $\mathrm{S}$ iff $\mathrm{S}$ neither believes that $\mathrm{p}$ nor that $\neg \mathrm{p}$ is empirically inadequate. This is because sentences of the form $\ulcorner$ I believe that p, but if $\neg p, q\urcorner$ sound perfectly natural, while sentences of the form $\ulcorner$ I know that $p$, but if $\neg p, q\urcorner$ and $\ulcorner p$, but if $\neg p, q\urcorner$ sound terrible:

\footnotetext{
${ }^{17}$ It is to be implicit through this section that unless stated otherwise we are restricting attention to canonical uses of the indicative conditional.
} 
(30) a. I believe that Jim is at home listening to The Mollusk, but if he's at the office then he probably isn't listening to music at all.

b. ?? I know that Jim is at home listening to The Mollusk, but if he's at the office then he probably isn't listening to music at all.

c. ?? Jim is at home listening to The Mollusk, but if he's at the office then he probably isn't listening to music at all.

Given a belief-theoretic implementation of opEnNEss, (30a) should have the feel of its (b-c) counterparts, when in fact it seems perfectly fine. So much the worst for the belief-theoretic implementation.

\subsection{Against certainty-theoretic conceptions of OPENNESS}

The second problem with the belief-theoretic analysis of openness should come as no surprise: the phenomenon made salient by conspiracy conditionals is that there are some contexts in which one has to do more than know a proposition or its negation to get the infelicity of the relevant conspiracy conditional.

With this in mind, the natural thought is to understand openness in terms of an epistemic relation that entails knowledge without being entailed by knowledge itself. Let us use Cartesian certainty as a placeholder for such a relation, intending that its interpretation be left as something of a black box, modulo the following two stipulations. First, if $\mathrm{S}$ has Cartesian certainty toward $\mathrm{p}$, then $\mathrm{S}$ knows p. Second, the kinds of propositions to which we stand in the Cartesian certainty relation are generally quite limited. In particular, we will assume that an ordinary adult $\mathrm{S}$ does not stand in this relation to the propositions expressed by sentences like:

$\left(\mathbf{P}_{1}\right) \mathrm{S}$ has hands.

$\left(\mathbf{P}_{2}\right)$ Donald Trump is the president of the United States.

$\left(\mathbf{P}_{3}\right)$ Oswald shot Kennedy.

For on the assumption that an ordinary adult does not have Cartesian certainty of any of $\left(\mathrm{P}_{1}\right)-$ $\left(\mathrm{P}_{3}\right)$, it is straightforward to see how, given this conception of OPENNESS, the corresponding conspiracy conditionals could be appropriately assertable in the canonical way.

But now a new challenge arises. Unless the proponent of the certainty-theoretic conception of openness wants to defend a highly revisionary theory of the norms of assertion-one that says that with the exception of tautologies and the like no one has ever asserted anything properly-she better predict that sentences like $\left(\mathrm{P}_{1}\right)-\left(\mathrm{P}_{3}\right)$ are sometimes (indeed often) assertable. Consequently, she must reject:

ASSERTION In every context $c$ : If $\ulcorner$ It is epistemically appropriate for $\mathrm{S}$ to assert that $\mathrm{p}\urcorner$ is true in $c$, then $\ulcorner$ It isn't open for $\mathrm{S}$ whether $\mathrm{p}\urcorner$ is true in $c$. 
This is because on the (Cartesian) certainty view, not being open is an extremely demanding epistemic relation, one that a normal person will context-invariantly fail to stand in to the propositions expressed by $\left(\mathrm{P}_{1}\right)-\left(\mathrm{P}_{3}\right)$. And this in turn means the proponent of such a view cannot deliver:

COORDINATION In every context $c$ : If $\ulcorner$ It is epistemically appropriate for $S$ to assert that $\mathrm{p}\urcorner$ is true in $c$, then $\ulcorner$ It is inappropriate for $S$ to assert 'If $(\neg)$ p, q' in the canonical way $\urcorner$ is true in $c$.

What COORDINATION says, in words, is that whether it is appropriate to assert an indicative conditional in the canonical way depends on whether you are (epistemically) in a position to assert its antecedent unembedded.

We should be loathe to give up COORDINATION. Without it, it is not at all clear how we are to explain the badness of conjunctions like the following:

(31) It's a known fact that Oswald shot Kennedy. ?? But if he didn't shoot Kennedy, then someone else did.

(32) I'll hit a kick serve out wide next point. ?? If I have hands, then I'll make sure to put extra top spin on it.

(33) Tomorrow we're going to the White House to see Trump speak. ?? If there is a president of the United States, then tomorrow we'll see the president speak.

If the norms governing canonical uses of the indicative conditional are autonomous with respect to the norms governing assertion more broadly, then there is no principled reason to expect the assertability of $p$ to tell against the assertability of $\ulcorner$ If $(\neg) p, q\urcorner$. And yet there appears to be no single context in which one is permitted to assert both $\mathrm{p}$ and $\ulcorner$ If $(\neg) \mathrm{p}, \mathrm{q}\urcorner \cdot{ }^{18}$ To account for this fact, the proponent of the certainty-theoretic conception of OPENNESS will have to posit the existence of a principle that replicates the intended effects of COORDINATION by fiat. But this very much looks like the kind of phenomenon that ought to be explained rather than merely taken for granted.

\subsection{Against common ground-theoretic conceptions of OPENNESS}

Having rejected belief- and certainty-theoretic analyses of openness, the final proposal we will consider ties facts about what is open in context to the conversational common ground: the set of

\footnotetext{
${ }^{18}$ Since it is possible to shift contexts mid-sentence, we should expect it to be possible to hear good readings of (31)(33). But this is no threat to COORDINATION, for there are also good readings of sentences like (34) and (35):

(34) Kansas is flat, but it's not flat.

(35) Even if I don't know that I have hands, I obviously know that I do.
} 
possibilities consistent with all that has been mutually presupposed and asserted by a context's conversational participants. ${ }^{19}$ On this way of understanding the openness relation, a proposition $\mathrm{p}$ is open in a context $c$ iff neither $\mathrm{p}$ nor $\neg \mathrm{p}$ is entailed by the conversational common ground associated with $c$. So given OPENNESS, the assertion of an indicative conditional $\ulcorner$ If $p$, $q\urcorner$ is appropriate in $c$ only if the answer to the question of whether $\mathrm{p}$ is not common ground in $c$.

Assuming that an assertion of $\mathrm{p}$, if accepted, has the effect of making $\mathrm{p}$ common ground, then it is straightforward to see why an assertion of $\ulcorner p$ but if $\neg p, q\urcorner$ or $\ulcorner p$ and if $p, q\urcorner$ would always seem inappropriate on this view (when made in the canonical way). So the common ground view appears to avoid the problems that beset the belief- and certainty-theoretic interpretations of OPENNESS.

Despite its initial attraction, however, the view faces its own set of challenges. Most prominently, it fails to explain some of even the most basic data motivating principles like OPENNESS in the first place. Here I have in mind examples like (3) ('If I had a bagel for breakfast this morning, then I went out for brunch with Jim'). As was argued in §2, an assertion of (3) will in most ordinary contexts be puzzling. But there should be nothing strange about it by the lights of the common ground interpretation of OPENNESs, since both the antecedent and its negation are compatible with the common ground.

Similarly, the common ground view fails to explain the badness of speeches of the form $\ulcorner\mathrm{I}$ know whether p. If $(\neg) p, q\urcorner$. Consider, e.g.:

(36) I know whether Oswald shot Kennedy. ?? If Oswald shot Kennedy, then he probably acted alone.

(37) I know whether Trump is the president. ?? If Trump isn't the president then Pence is.

There seems to be no context in which either (36) or (37) can be felicitously asserted in the canonical way. So it better be that an assertion of $\ulcorner\mathrm{S}$ knows whether $\mathrm{p}\urcorner$ has the effect of making an assertion of $\ulcorner$ If $(\neg) \mathrm{p}, \mathrm{q}\urcorner$ inappropriate. But since an assertion of $\ulcorner\mathrm{S}$ knows whether $\mathrm{p}\urcorner$ adds neither p nor $\neg \mathrm{p}$ to the common ground, it's not clear why, according to the common groundtheoretic conception of OPENNESS, there should be any impropriety at all.

Of course, OPENNESS is only meant to provide a necessary condition on the assertability of an indicative conditional. So the fact the common ground-theoretic interpretation of OPENNESS cannot explain the badness of (3) or of (36)-(37) is not itself enough to show there is anything wrong with that interpretation. But what would be enough to show that there is a problem with that interpretation would be to show the difficulty of finding other principles capable of doing the work that OPENNESS can do when 'is open' is interpreted as 'knows'.

This turns out to be quite difficult indeed. Aside from IGNORANCE, what principle can the proponent of the common ground view appeal to to explain the badness of either (3) or (36)(37)? Their best bet seems to be something like the following: S's (canonical) assertion of $\ulcorner$ If

${ }^{19}$ The vague characterization just given suffices for present purposes, but see, e.g., Stalnaker $(1999,2002)$ and the citations therein for explication. 
$p$, $q\urcorner$ is inappropriate just in case: were $S$ to assert $p$ (or $\neg p$ ), the proposition $p$ (or $\neg p$ ) would become common ground.

Now, there's a sense in which this proposal works for (3): ${ }^{20}$ it is plausible that the proposition that I had a bagel for breakfast this morning would have become common ground had I asserted 'I had a bagel for breakfast this morning', and so given the proposal we have reason to expect an assertion of (3) to seem inappropriate.

But it should also be clear that the proposal is only superficially helpful. What is it about the proposition that I had a bagel for breakfast this morning that makes it so that if I were to assert it, it would be added to the common ground? Certainly not all propositions are like this. So the proposal raises the more general question of under what conditions a speaker $\mathrm{S}$ is related to a proposition $\mathrm{p}$ such that: were $\mathrm{S}$ to assert $\mathrm{p}$, $\mathrm{p}$ would become common ground. And any plausible answer to this question will start by invoking some kind of epistemic standard $E$, and then go on to claim that interlocutors will accept S's assertion that p just in case they take S's epistemic state to meet $E$ with respect to $\mathrm{p}$. So now the overall view is: $S$ 's assertion of $\ulcorner$ If $\mathrm{p}, \mathrm{q}\urcorner$ is inappropriate just in case: either (i) p is common ground, or (ii) with respect to the question of whether p, S's epistemic position meets $E$. And supposing (uncontroversially) that a necessary condition on a proposition's already being in the common ground is that it passes whatever test a proposal to update the common ground must pass, then the view is equivalent to: S's assertion of $\ulcorner$ If $\mathrm{p}, \mathrm{q}\urcorner$ is inappropriate just in case: with respect to the question of whether $\mathrm{p}$, S's epistemic position meets $E$. And this is simply COORDINATION with the stipulation that 'is open' is to be analyzed in terms of $E$. The common ground interpretation of OPENNESS does nothing other than replace one placeholder notion ('is not open') with another ('meets the standards required to enter the common ground').

In short, then: the common ground-theoretic conception of OPENNESS tells us why an indicative conditional will be inappropriate to assert when the answer to the question of whether its antecedent is true is already common ground. But it tells us nothing about the conditional's assertability when it is not. And filling in this gap has the effect of making the appeal to common ground superfluous. The real work is done by whatever epistemic standards interlocutors apply when deciding whether to add a new proposition into the common ground, not the facts about the common ground itself.

\subsection{What's left?}

The lesson we just learned from the discussion of the common ground-theoretic conception is that the interpretation of 'is open' must be tied to epistemic standards of some sort of other. And the lesson we learned prior to that one is that the epistemic standards cannot be those of belief or Cartesian certainty. So what are they?

${ }^{20}$ It's not at all clear it works for (36)-(37), but the objection I'm about to make to its treatment of (3) will get at the same fundamental problem in a simpler way. 
If the epistemic standards are those of knowledge, then in place of OPENNESS and ASSERTION we'll have IGNORANCE and KNA

IGNORANCE In every context $c$ : if $\ulcorner$ S knows whether $\mathrm{p}\urcorner$ is true in $c$, then $\ulcorner$ It is inappropriate for $\mathrm{S}$ to assert the indicative conditional 'If $\mathrm{p}, \mathrm{q}$ ' in the canonical way $\urcorner$ is true in $c$.

KNA In every context $c$ : If $\ulcorner$ It is epistemically appropriate for $S$ to assert that $\mathrm{p}\urcorner$ is true in $c$, then $\ulcorner\mathrm{S}$ knows that $\mathrm{p}\urcorner$ is true in $c$.

But obviously the moderate invariantist cannot accept this, for we know from $\S 4$ that the openness facts shift in ways that the moderate invariantist says knowledge cannot.

Thus, if the moderate invariantist wants to reject IGNORANCE (without abandoning OPENNESS entirely), she will have to choose between two options, broadly construed: either (i) connect the judgments that motivate generalizations like IGNORANCE and KNA to some familiar but yet to be seen epistemic notion-something other than belief, Cartesian certainty, or knowledge; or (ii) leave 'is open' as an unanalyzed primitive. I will conclude this section with two worries-one empirical, one conceptual-that apply regardless of which of these two options one might pursue.

The empirical worry is that by severing the connection between 'knows' and 'is open', it becomes difficult to explain quite a lot of the intuitive data that compels theorists to posit those principles like KNA and IGNORANCE in the first place. If there is not some general principle to the effect of $\ulcorner$ Assert $\mathrm{p}$ only if you know that $\mathrm{p}\urcorner$, then what explains the naturalness of certain stock challenges to assertions, e.g.: 'How do you know that?', 'You don't know that', etc.? Likewise: as was observed in $\S 2$, when someone (say $S$ ) asserts $\ulcorner$ If $\mathrm{p}, \mathrm{q}\urcorner$ in a situation in which we are inclined to accept the truth of $\ulcorner S$ knows whether $\mathrm{p}\urcorner$, there is an inclination to respond with puzzlement along the lines of: ‘What do you mean if p? Don't you know whether p? $\urcorner$. Note that this is exactly what happens in the case of (3) ('If I had a bagel for breakfast this morning, then I went out for brunch with Jim'): it is because we take people to know what they had for breakfast that morning that an assertion of a conditional beginning 'If I had a bagel for breakfast this morning...' strikes us as bizarre. Is this pattern of judgments the result of a mistake? Or does it just so happen that by coincidence, whatever epistemic relation is denoted by 'is open' in standard contexts is the same as (or suitably related to) the one denoted by 'knows'?

The conceptual worry is more of a tu quoque against the moderate invariantist. But given that she more than anyone has reason to want to deny principles like IGNORANCE, having it on the table will help clarify some of IGNORANCE's attraction. The worry is this. One who gives a theory of openness in terms of something other than 'knows' must reject a hypothesis many moderate invariantists are likely to find antecedently appealing. It is the hypothesis that knowledge is what determines (e.g.) the norms of assertion and the implicatures of indicative conditionals. In rejecting this hypothesis, the moderate invariantist robs the concept of knowledge of a lot of explanatory power. Worse, in positing this basic yet (apparently) deeply engrained epistemic 
notion, the moderate invariantist faces a renewed threat from all sorts of other knowledgeobviating views. Given that not being open-whatever that amounts to-is what governs assertion and the pragmatics of indicative conditionals, one might wonder whether it could have a similar role in explaining our judgments about evidence and action. Better to tie principles like OPENNESS and ASSERTION to a contextualist account of 'knows' and thereby allow knowledge to maintain much of its explanatory power.

\section{An error theory about conspiracy conditionals?}

Let's take stock. $\S 4$ observed that conspiracy conditionals seem appropriately assertable in a variety of ordinary contexts, and then pointed out that if moderate invariantism is to avoid being sunk by this fact, then at least one of the following four claims must be true: (i) conspiracy conditionals are never assertable in the canonical way; (ii) some principle other than IGNORANCE is better suited to capture the generalizations outlined in §2; (iii) our judgments about conspiracy conditionals are systematically mistaken; or (iv) it is not possible to sincerely assert a conspiracy conditional in the canonical way while retaining one's knowledge of its antecedent. We know from $\S 5$ and $\S 6$ respectively that (i) and (ii) are false. This leaves (iii) and (iv), which are addressed in this section and the next.

With respect to (iii), the task of explaining away ordinary judgments about knowledge is familiar territory for the moderate invariantist. It is well known that the facts about our ordinary judgments about knowledge ascriptions — sentences of the form $\ulcorner\mathrm{S}$ knows whether $\mathrm{p}\urcorner$-are at least somewhat in tension with the moderate invariantist's semantics for 'knows'. Accounting for these facts has forced her to develop error theories. One might wonder whether those same error theories could (and if so, should) be called upon to explain our intuitions about conspiracy conditionals. This section will argue that they cannot, and in fact that it is plausible that no error theory of our intuitive judgments about conspiracy conditionals can.

\subsection{The old dialectic}

Let's say that the purely epistemic factors that go into determining whether a subject $\mathrm{S}$ knows a proposition p are exhausted by S's beliefs and evidence-where 'evidence' is to be understood in an intuitive, theory-neutral way-as well as the truth of the matter about $\mathrm{p}^{21}$

As is well known, there can be pairs of situations that agree on the purely epistemic factors relevant to the relationship between a subject $S$ and proposition $\mathrm{p}$, and yet in which the truth of the knowledge ascription $\ulcorner\mathrm{S}$ knows that $\mathrm{p}\urcorner$ is judged to differ. ${ }^{22}$ For example, it is not at all

\footnotetext{
${ }^{21}$ Supposing we want the difference between Gettiered and non-Gettiered subjects to count as "purely epistemic" (which I take to be the presumptive view), facts about the etiology of S's belief and perhaps the hostility of her environment will probably have to factor in too. But for our purposes it is safe to ignore these compilcations.

${ }^{22}$ For just a small sampling of the literature on this phenomenon, with a particular focus on work that offers ordinary language evidence in favor of alternatives to moderate and skeptical invariantism, see, e.g., Austin (1946); Cohen
} 
difficult to find contexts in which for any of $\left(\mathrm{P}_{1}\right)-\left(\mathrm{P}_{3}\right)$, intuitively $\left\ulcorner\mathrm{S}\right.$ knows that $\left.\left(\mathrm{P}_{n}\right)\right\urcorner$ is true. However, it is also not at all difficult to find contexts in which holding the purely epistemic facts about $S$ fixed, it is the negation of $\left\ulcorner\mathrm{S}\right.$ knows that $\left.\left(\mathrm{P}_{n}\right)\right\urcorner$ that is intuitively true. Contexts in which the following are natural tend to do the trick:

(38) Unless S has discovered some way of proving that she isn't a handless BIV, S doesn't know that she has hands.

(39) S doesn't know that Trump hasn't had a fatal heart attack in the past few moments, so S doesn't know that Trump is still the president of the United States.

(40) There are too many unanswered questions surrounding Oswald's involvement in Kennedy's assassination for $\mathrm{S}$ to know for sure that Oswald shot Kennedy.

Thus, marginal cases aside, the following empirical fact is common ground to those who theorize about knowledge: that there can be pairs of situations in which all the purely epistemic factors relevant to $S$ and $p$ are fixed and yet the truth of the knowledge ascription $\ulcorner S$ knows that $\mathrm{p}\urcorner$ is nonetheless judged to vary by competent speakers of the language. By extension, it is common ground that's one theory of knowledge must account for this fact. This is not to say that it must codify it into the semantics for 'knows' itself; it's just that if the theory takes competent speakers to be judging or speaking falsely, it better explain why this happens.

Enter the moderate invariantist's error theory. The first half of the error theory is the empirical half. It identifies some psychological mechanism—which we'll call $X$-and observes that the presence of $\mathrm{X}$ correlates systematically with a tendency to deny the ascriptions that, by the lights of the theory, ought in every context be affirmed. The second half is the exculpatory half. It provides reasons to believe that the presence of $\mathrm{X}$ explains these variations in a way that relieves the pressure to have one's semantics for 'knows' account for them.

What is $\mathrm{X}$, the mechanism the error theory finds predictive of the variations it seeks to explain away? There are, in general, two kinds of sub-mechanisms discussed in the literature: stakes and salience. ${ }^{23}$ Both can be further broken down into cases affecting the ascriber $(A)$ and cases affecting the subject $(S) .{ }^{24}$ This gives us four factors in total: what the stakes are for $A$, what the stakes are for $S$, what's salient to $A$, and what's salient to $S$. We'll say more about what these factors amount to in a moment. For present purposes it is enough if one's understanding of the nature of these mechanisms is mostly exhausted by one's knowledge of the ordinary meaning of the words 'stakes' and 'salience'.

(1986); Lewis (1996); Cohen (1999); DeRose (1992, 1995, 2002); Hawthorne (2004); Schaffer (2005b, 2007); Stanley (2005); Schaffer \& Szabo (2013).

${ }^{23}$ The literature here is truly massive. See, e.g., Rysiew (2001); Fantl \& McGrath (2002, 2009); Hawthorne (2004, §4.2); Bach (2005); Schaffer (2005a); Williamson (2005); Stanley (2005); Adler (2006); McGrath (2007); Nagel (2008, 2010b); May et al. (2010); Reed (2010); Weatherson (2012); Buckwalter \& Schaffer (2015); Roeber (2018). Note that many of these authors-in particular those who defend subject-sensitive accounts of knowledge-build certain aspects of $X$ into the semantics of 'knows' itself. As we will see in $\S 8$, whether $X$ goes into one's semantics or one's error theory makes no difference to the problem posed by conspiracy conditionals.

${ }^{24}$ In the case of first-personal knowledge ascriptions $A=S$. 
The empirical half of the error theory says that as you vary the stakes or what's salient (perhaps for $A$, perhaps for $S$ ), you should expect $A$ 's judgments about the truth of $\ulcorner\mathrm{S}$ knows that $\mathrm{p}\urcorner$ to vary. In particular, as what is at stake on whether $\mathrm{p}$ becomes higher, and as (metaphysical) possibilities in which $\neg$ p become more salient (again perhaps to $A$, perhaps to $S$ ), $A$ will become more inclined to judge that $\ulcorner\mathrm{S}$ knows that $\mathrm{p}\urcorner$ is false.

The exculpatory half of the error theory then argues that we have reason to expect that these sorts of variations in stakes and salience should cause errors in ordinary attributions of knowledge. For two prototypical examples of this half of the error theory (as well hints about the nature of stakes and salience), see Williamson's (2005, p. 226) line:

[Possibilities of error] may be psychologically salient because the practical costs of error are high for the subject or the ascriber, or simply because they have been evoked in vivid and convincing detail. One effect of fictional violence on television is to make viewers overestimate their chances of being the victims of violent crime: they suffer an illusion of danger. Might not an illusion of epistemic danger result from exposure to lurid stories about brains in vats, evil demons, painted mules, or gamblers who bet the farm?

As well as Hawthorne's (2004, p. 164):

[Psychologists] emphasize the role played by the 'availability' heuristic as a distorting influence on our judgments of risk: in many cases, our estimation of the likelihood of an event is affected by the ease with which we can recall or imagine it...Applied to the issue at hand, the availability heuristic may help to explain our tendency to skeptical overprojection. When certain non-knowledge-destroy counterpossibilities are made salient, we overestimate their real danger; as a result, we may find ourselves inclined to deny knowledge to others in cases where there is in fact no real danger of error. ${ }^{25}$

So, to summarize: the moderate invariantist's error theory of our intuitions about knowledge ascriptions is composed of two hypotheses. First, that as a matter of empirical fact, mechanism $\mathrm{X}$-i.e., variations in what is at stake for or salient to ascriber and/or subject-is what explains the variability in our intuitive judgments about the truth of various mundane knowledge ascriptions. And second, that the presence of $\mathrm{X}$ is the kind of thing that can sympathetically explain why otherwise competent speakers so often err in their use of 'knows'.

\footnotetext{
${ }^{25}$ Nagel (2010b) offers an extended criticism of Hawthorne and Williamson's use of the availability heuristic in their error theories. Her preferred account appeals to the phenomenon of 'epistemic egocentricism', whereby people fail to suppress privileged information (i.e. what they know or are concerned with) in evaluating the judgments of others. The complaints about Williamson and Hawthorne's error theories will apply just as much to hers.
} 


\subsection{The new dialectic}

Let us suppose that the error theory just described is a contender as concerns our intuitions about knowledge ascriptions. Should we think that it works as an error theory of our judgments about conspiracy conditionals? Well, that depends on whether the two components of the error theory about the former can be transposed into an error theory about the latter. And on that issue I think that the empirical half of the error theory is almost surely inadequate, and that to the extent that it can be recovered, it is only in virtue of compromising the exculpatory half.

The empirical half of the moderate invariantist's error theory associates variations in our judgments about ascriptions with changes in stakes and salience. Since by IGNORANCE the relevant agent's epistemic state is the speaker's, for present purposes the distinction between ascriber and subject is irrelevant. Taking stakes and salience in turn, I will argue that although the presence of factors might be sufficient to license the assertion of a conspiracy conditional, it is not plausible that their presence is necessary for it. But absent the necessity claim, the error theory is inadequate.

Starting with stakes, it should be clear that an appeal to variations in what $S$ has riding on the truth of $\mathrm{p}$ is a non-starter as part of a general account of the judgment that $\mathrm{S}$ may sometimes appropriately and canonically assert a conspiracy conditional of the form $\ulcorner$ If $\mathrm{p}, \mathrm{q}\urcorner$. It may be the case that p's being of sufficient practical concern to $S$ licenses an assertion of the conspiracy conditional, but it is not the case that p must be that way. That is to say, for many adults $\mathrm{S}$, there are a variety of propositions p such that: (i) according to the moderate invariantist, the proposition expressed by $\ulcorner\mathrm{S}$ knows that $\mathrm{p}\urcorner$ is true in every context; (ii) the question of whether $\mathrm{p}$ is more or less irrelevant to S's practical interests; and yet (iii) there are contexts in which $\mathrm{S}$ (or anyone else) may felicitously assert the conspiracy conditional $\ulcorner$ If $(\neg)$ p, then $q\urcorner$. Most of the examples considered in $\S 4$ have this feature, but to drive the point home: imagine looking up the weather in any locale you don't care about, and consider the conspiracy conditional:

(41) If it is raining there, then the weather report is accurate.

Clearly you may felicitously assert this conspiracy conditional even when you have nothing riding on the weather in that locale. Concerns of stakes, practical interests, etc., are thus orthogonal to the issue of what to make of the felicitous use of conspiracy conditionals. All the worse for error theories that rely on them.

The upshot is that the error-theoretic appeal to $\mathrm{X}$ will have to lean heavily on the salience condition to explain away conspiracy conditionals. What does this condition amount to? Well, it is not enough that $\mathrm{S}$ merely consider the possibility that $\neg$ p. For one, it is easy enough to do that in a context in which the corresponding conspiracy conditional seems unassertable. ${ }^{26}$

${ }^{26}$ To borrow from an example of Hawthorne's (2004, p. 64), just because I'm watching The Matrix doesn't mean it will be appropriate to assert something like:

(42) If I'm watching a movie right now, then it's The Matrix. 
For another, if the exculpatory half of the moderate invariantist's error theory is to be plausible, the attention one gives to these possibilities has to be the kind that would explain why otherwise rational and competent speakers fail to follow the basic rules about the use of 'knows'. So presumably $\neg$ p is salient to $S$ in the relevant way just in case $S$ is taking the metaphysical possibility that $\neg$ p seriously. What does taking a possibility seriously amount to? Nothing in the literature makes the notion altogether clear. We'll thus have to resort to taking those who have invoked the mechanism in their theorizing at their word-so see, for instance, the Williamson and Hawthorne passages from above, as well as the famous passage of Lewis's (1996, p. 549):

Let your paranoid fantasies rip - CIA plots, hallucinogens in the tap water, conspiracies to deceive, old Nick himself — and soon you find that uneliminated possibilities of error are everywhere.

These vague suggestions are enough to get the argument going. Consider again any of the following conspiracy conditionals:

(1) If Oswald didn't shoot Kennedy, then someone else did.

(23) If Federer defeated Nadal in straight sets, then this report is accurate.

(27) If nature is uniform, then induction is a reliable means of forming true beliefs.

If the diagnosis of error in terms of salience is to be plausible, it better be that we find these conditionals natural only when we are in the sorts of psychological states alluded to by Williamson, Hawthorne, and Lewis: those involving paranoid fantasies, the vivid imaginings of metaphysical counterpossibilities, etc. But the issue is that these are not the only situations in which conspiracy conditionals sound natural. One can find the evidence of a conspiracy as ludicrous as one wants while still finding it appropriate to assert in the canonical way that if is Oswald didn't shoot Kennedy, then someone else did. The point is especially striking when it comes to conspiracy conditionals whose antecedents concerns events in the future, such as:

(29) If this fair coin lands heads 1,000 times in a row, then most onlookers will be quite confident that the coin is double-headed. ${ }^{27}$

(43) If Trump isn't president tomorrow, then either he'll have died or resigned by then.

(44) If I manage to acquire enough money for an African safari this year, then I'll definitely go on one.

I submit that these conditionals do not at all have the feel of being symptomatic of an overfixation on obscure possibilities of error. ${ }^{28}$

\footnotetext{
${ }^{27}$ See footnote 16.

${ }^{28}$ Note too that even if we had a view on which the mere consideration of possibilities of error (whether vividly or not)
} 
But by way of driving the point home, it is worth observing an important contrast between our judgments about skeptical knowledge ascriptions and our judgments about conspiracy conditionals. For most of the mundane propositions the moderate invariantist takes many adults to context-invariantly know- $\left(\mathrm{P}_{1}\right)-\left(\mathrm{P}_{3}\right)$ continuing to be serviceable examples-it takes some effort to get speakers to start actually saying that they aren't known. We should thus expect discourse initial assertions of knowledge denials of $\left(\mathrm{P}_{1}\right)-\left(\mathrm{P}_{3}\right)$ to generally seem strange, as they typically will occur in contexts in which the truth of their complements are more or less taken for granted.

Is this prediction born out by the facts? Well, imagine a friend were to open up a conversation with something like:

(45) We don't know whether Trump is president of the United States.

(46) We don't know whether Oswald shot Kennedy.

Speaking for myself, I would expect to find these assertions a bit jarring. I'd want to know whether they had recently uncovered something new about Trump or the Kennedy assassination, or if they knew something about my evidence that I didn't. And until presented with something of that sort, I would probably just disagree with them. But the intuitions are different with conspiracy conditionals. A discourse initial assertion of (1) ('If Oswald didn't shoot Kennedy, then someone else did') is a noticeable improvement, as its standing in the philosophical literature suggests. Likewise is an assertion of (e.g.):

(20) If Trump is no longer the president of the United States, then it is surprising we haven't heard about that.

I might still find these speeches a bit puzzling—for instance I might what prompted the person to say such a thing. But I wouldn't find myself inclined to think she had implied anything false. This contrast casts yet further doubt on the use of the mechanisms of salience in an account of our intuitions about conspiracy conditionals. It simply strains credulity to think that what explains the difference in the (discourse initial) acceptability of (e.g.) (45) and (20) is that hearing (20) causes me to take possibilities in which Trump is dead sufficiently seriously, while hearing (45) does not.

I thus conclude that the felicitous use of conspiracy conditionals has nothing important to do with facts about salience. And since we also know it has nothing important to do with facts about stakes, it is unclear whether there is an error theory that could plausibly explain away the impression that canonical uses of conspiracy conditionals are sometimes appropriate.

could be enough to cloud our judgments about knowledge-and mind you this would put a lot of strain on the "error" part of the error theory-I doubt that even this is always involved in the circumstances in which ordinary speakers assert conspiracy conditionals. For example: if after asserting (44) you were to ask me 'How might you acquire enough money for an African safari?' I could well reply 'I have absolutely no idea. It may well be impossible. But if I somehow manage to do it I'm going to go on one'. It is hard to see such speeches as being in keeping with the kinds of ideas suggested by Williamson, Hawthorne, and Lewis. 


\section{Do conspiracy conditionals show that knowledge is fragile?}

In the absence of a plausible error theory, our judgments about conspiracy conditionals need to be accommodated rather than explained away by our theory of knowledge. And since we know there are contexts where a speaker $\mathrm{S}$ who has all the standard evidence regarding the Kennedy assassination can felicitously assert conditionals like (1, 'If Oswald didn't shoot Kennedy, then someone else did') in the canonical way, we know there must be contexts in which $\ulcorner$ S knows whether Oswald shot Kennedy $\urcorner$ expresses a falsehood. Moderate invariantism says that, holding fixed the purely epistemic facts about S, $\ulcorner$ S knows whether Oswald shot Kennedy $\urcorner$ expresses a truth in all contexts. So either moderate invariantism is false, or-contrary to the supposition we've been making throughout the paper-the circumstances in which conspiracy conditionals like (1) are assertable in the canonical way are invariably those in which the purely epistemic factors concerning $S$ have not been held fixed. That is: whenever $S$ in a situation in which she can felicitously assert (1) in the canonical way, it's because $\ulcorner$ S doesn't know whether Oswald shot Kennedy $\urcorner$ expresses a context-invariant truth.

This idea forms the basis of the fourth and final response we will consider on behalf of the moderate invariantist. ${ }^{29}$ To help sharpen it, let us assume that some psychological mechanism or another is responsible for the shifts in our attitudes toward the canonical assertability of conspiracy conditionals. We'll call it mechanism $Y .^{30}$ By assumption, whenever $Y$ is present in $\mathrm{S}$ with respect to $\mathrm{p}, \mathrm{S}$ will be disposed to take the conditional $\ulcorner$ If $\mathrm{p}, \mathrm{q}\urcorner$ to be assertable in the canonical way. The question, then, is whether it is plausible that the presence of $\mathrm{Y}$ in $\mathrm{S}$ with respect to $\mathrm{p}$ means that $\mathrm{S}$ 's purely epistemic factors have shifted enough for $\mathrm{S}$ to no longer know whether $\mathrm{p}$.

The truth of moderate invariantism hinges on the answer to this question. And as should come as no surprise I think the answer is a negative one: given the moderate invariantist's preferred theory of knowledge, it is not plausible that the presence of $Y$ destroys it. The reason why is that the moderate invariantist only has two purely epistemic factors to work with: the facts about S's evidence-where again we are understanding 'evidence' in an intuitive, theoryneutral way-and the facts about S's beliefs. ${ }^{31}$ It seems clear that the situations in which a conspiracy conditional like (1) is assertable needn't be those in which one's evidence regarding the Kennedy assassination has weakened, so I'm going to set aside the idea that the presence of $\mathrm{Y}$ destroys knowledge by destroying evidence. So the view in question will be one that says that the presence of $Y$ destroys knowledge by destroying belief. That is to say: if one has the standard sorts of evidence concerning the Kennedy assassination but is disposed to assert (1) sincerely and in the canonical way, it must be that one fails to believe (and therefore fail to know) that

\footnotetext{
${ }^{29}$ Thanks to an anonymous reviewer for pressing me to consider this response.

${ }^{30}$ Although we don't know much about mechanism Y, we do know from the previous section that $\mathrm{Y} \neq \mathrm{X}-\mathrm{i}$.e., combinations of facts about stakes and salience.

31 The facts about S's environment can count as purely epistemic factor too, but obviously those are not what shift in accordance with our judgments about the assertability of conspiracy conditionals.
} 
Oswald shot Kennedy. ${ }^{32}$

The issue is that this claim is either straightforwardly false or explanatorily inadequate. Which it is depends on how the moderate invariantist chooses to interpret 'belief'. If she has in mind the ordinary notion-i.e., the one we give voice to when we think or say things like $\ulcorner\mathrm{S}$ believes that $\mathrm{p}\urcorner$ - then the claim is straightforwardly false. As we know from §6.1's discussion of belief-theoretic interpretations of IGNORANCE, there is no barrier to being disposed to assert $\ulcorner$ If $\mathrm{p}, \mathrm{q}\urcorner$ in the canonical way while retaining one's belief that $(\neg)$ p. Speeches like

(30a) I believe that Jim is at home listening to The Mollusk, but if he's at the office then he probably isn't listening to music at all.

are perfectly fine. ${ }^{33}$

So the moderate invariantist must have some other notion of 'belief' in mind. Perhaps it's the quasi-technical notion of full belief, which we might think of along the lines of the ordinary concept of being sure. ${ }^{34}$ But in that case the response is explanatorily inadequate. For one, if 'belief' is understood in this quasi-technical way, it's far from clear that knowledge actually entails belief. ${ }^{35}$ And even if it does (say because we're stipulating as much), there is a question of what explains the loss of belief in these cases. Again, we know from the previous section that it's not like the impression that (1) is assertable in the canonical way invariably corresponds to a loss of confidence in the proposition that Oswald shot Kennedy. Indeed, what seems to explain why S would assert (1) rather than (say) 'Oswald shot Kennedy' - and thus what would explain why S fails to fully believe that Oswald shot Kennedy-is S's impression that for all S knows, someone other than Oswald shot Kennedy. So the story would really have to be something like this: S starts off knowing Oswald shot Kennedy, for some reason comes to falsely believe that she doesn't know it, and as a result of forming this belief stops believing and thereby stops knowing that Oswald shot Kennedy. As a result, S's belief that she doesn't know whether Oswald shot Kennedy is laundered into a truth, and the conspiracy conditional becomes assertable in the canonical way.

The issue with this story is that it is implausible in essentially the same way the error theory is implausible: it requires us to think that the situations in which we're inclined to assert a conspiracy conditional in the canonical way are generally preceded by systematic errors in our assessment of our knowledge. And given that the situations in which conspiracy conditionals seem canonically assertable can be those in which none of the usual error culprits are present (high stakes, salient metaphysical counter-possibilities, etc.), we should be reluctant to attribute such errors to ourselves.

${ }^{32}$ Cf. Nagel (2010a), who defends a similar line on behalf of the moderate invariantist in response to challenges from our judgments about knowledge ascriptions in high-stakes situations.

${ }^{33}$ For further evidence that it is implausible that speakers who assert conspiracy conditionals in the canonical way fail to have beliefs about the truth of those conditionals' antecedents, see, e.g., Hawthorne et al. (2016); Dorst (2019b); Rothschild (2019).

${ }^{34}$ For more on full belief see, e.g., Hintikka (1962); Stalnaker (1984); Williamson (2000); Buchak (2014); Greco (2015).

${ }^{35}$ See, e.g., Radford (1966); Stanley (2008); Beddor (Forthcoming). 
I conclude that the moderate invariantist is out of options. Conspiracy conditionals appear to be assertable in the canonical way. We have no independent reason to believe that there is a mismatch between appearance and reality. IGNORANCE is true, so situations in which one is in a position to assert a conspiracy conditional in the canonical way must be those in which by the lights of one's context, one doesn't know whether the conditional's antecedent expresses a truth. Since it is implausible that such contexts arise only when one's epistemic and/or doxastic state fails to meet the moderate invariantist's conditions for knowledge, moderate invariantism cannot be true.

\section{Knowledge in the face of conspiracy conditionals}

With moderate invariantism out of the way, we have three other options for our theory of knowledge, broadly construed: (i) skeptical invariantism; (ii) sensitive invariantism; and (iii) contextualism. I will conclude by briefly arguing for contextualism over skeptical and sensitive invariantism.

We'll start with skeptical invariantism. Being a brand of invariantism, this view has it that if you hold the underlying epistemic facts fixed, the truth of $\ulcorner S$ knows that $\mathrm{p}\urcorner$ in one context $c$ guarantees its truth in every other context $c^{\prime}$. But being a skeptical brand of invariantism, it also has it that for many adults $\mathrm{S},\left\ulcorner\mathrm{S}\right.$ knows that $\left.\left(\mathrm{P}_{n}\right)\right\urcorner$ is context-invariantly false when $\left(\mathrm{P}_{n}\right)$ is something like $\ulcorner$ Oswald shot Kennedy?

The exact details of the skeptic's underlying theory of knowledge will not matter for our purposes. So long as it meets the constraint just described, we know the view will have a straightforward explanation of why conspiracy conditionals are sometimes felicitous. The issue, however, is that we also know that the view will suffer from the defect $\$ 6.2$ argued the "certainty-theoretic" conception of OPENNESS suffers from. The defect is that it cannot offer a principled explanation of: (i) the fact that sometimes we may felicitously assert sentences like $\left(\mathrm{P}_{1}\right)$ ('Oswald shot Kennedy'), (ii) the fact that sometimes we may felicitously assert the corresponding conspiracy conditionals, and (iii) the fact that it is very difficult to felicitously assert the conjunction of these two things. In short: because by the skeptic's lights we know so little, it'll always be very easy to satisfy the demands of IGNORANCE. Why, then, is it also so easy for conspiracy conditionals to seem infelicitous?

Next there is sensitive invariantism about knowledge. ${ }^{36}$ In its traditional form sensitive invariantism is just like moderate invariantism, expect that the former takes the facts about what's at stake for or salient to the subject of a knowledge ascription to context-invariantly affect the ascription's truth-conditions. That is to say: the traditional sensitive invariantist takes the X-like features of the moderate invariantist's error theory about skeptical knowledge ascriptions and

${ }^{36}$ As I will use the label 'sensitive invariantism', one who believes knowledge is subject to "pragmatic encroachment" (and isn't a contextualist) is a sensitive invariantist. See Kim (2017) for a helpful overview. 
plugs them into the semantics for 'knows' directly. What this means is that, on the traditional sensitive invariantist's view, whether one knows a proposition depends not just on one's beliefs and evidence concerning that proposition; it also depends on what one has at stake on the truth of the proposition, and/or on whether one finds salient possibilities in which the proposition is false. Thus, you can have two agents $S_{1}$ and $S_{2}$ for whom the purely epistemic facts (beliefs, evidence, etc.) are identical as regards p, but for whom the facts about stakes and salience are not identical as regards $\mathrm{p}$, and as a result $\left\ulcorner\mathrm{S}_{1}\right.$ knows that $\left.\mathrm{p}\right\urcorner$ will be context-invariantly true while $\left\ulcorner\mathrm{S}_{2}\right.$ knows that $\left.\mathrm{p}\right\urcorner$ will be context-invariantly false.

Sensitive invariantism has been thought to capture much of the data that motivates contextualism about knowledge, while also avoiding some of contextualism's more exotic meta-semantic commitments. ${ }^{37}$ However, if $\S 7$ 's section's arguments against the moderate invariantist's error theory about conspiracy conditionals are sound, then they should tell more or less equally against the traditional sensitive invariantist's semantics for 'knows'. Again, to account for conspiracy conditionals like (1), the sensitive invariantist would have to argue that the psychological factors that make (1) seem assertable have the effect of destroying one's knowledge that Oswald shot Kennedy—no matter one's beliefs and evidence on the matter. But given that facts about stakes and salience do not always manage to distinguish situations in which (1) is assertable from situations in which it isn't, we can be confident that this view won't work. ${ }^{38}$

This leaves us with the contextualist's theory of knowledge. According to the contextualist, 'knows' (and its cognates) can be associated with different epistemic relations across different

${ }^{37}$ See, e.g., issues related to "semantic blindness" discussed by Schiffer (1996); Williamson (2005); Greenough \& Kindermann (2017).

${ }^{38}$ Of course it is open to the sensitive invariantist to modify her account of the non-epistemic factors to which knowledge is sensitive. Perhaps she can claim that the presence of Y factors (introduced in §8), like the presence of X factors, destroys knowledge. What are the Y factors? Again, it's not all together clear. But so long as there is some identifiable psychological feature responsible for S's taking herself to be in a position to canonically assert a conspiracy conditional, then it's always a theoretical option to take the absence of that psychological feature to be a non-epistemic precondition on knowledge.

Call this view extra-sensitive invariantism. Although I don't have a knockdown argument against it, I think there are at least two reasons to be reluctant to adopt it. First, extra-sensitive invariantism seems to me mysterious in a way that traditional forms of sensitive invariantism are not. Given the intuitive connections between knowledge, action, and deliberation, it's not so surprising that non-epistemic factors like what's at stake for S or what possibilities are salient to $S$ could make a difference to what $S$ knows. After all, reflection on what's at stake given p or on the various ways in which p could be false does tend to have the effect of making one's epistemic position with respect to p seem worse. But those who assert conspiracy conditionals in the canonical needn't have pessimistic thoughts on the strength of their evidence with respect to conditional's antecedent. (I take it that something like this is partially what explains $\S 7$ 's observation that there is a difference in discourse initial assertability of conspiracy conditionals and skeptical knowledge ascriptions.) This makes the claim that Y factors are knowledge-destroying feel especially ad hoc. Second, if we (the audience) are in a context in which we take $\ulcorner\mathrm{S}$ knows whether $\mathrm{p}\urcorner$ to express a truth and we hear $\mathrm{S}$ assert $\ulcorner$ If $\mathrm{p}, \mathrm{q}\urcorner$ in the canonical way, we won't always come to believe that $\ulcorner\mathrm{S}$ knows whether $\mathrm{p}\urcorner$ expresses a falsehood. Sometimes our reaction will be to think or say something like 「Why is S saying 'If p, q'? She knows whether p! ?. Indeed, this is the kind of reaction that back in §2 I claimed we might have to a person's asserting (3 'If I had a bagel for breakfast this morning, then I went out for brunch with Jim.'). If extra-sensitive invariantism is correct, however, such a reaction rests on a mistake. For if $\mathrm{S}$ is sincerely asserting $\ulcorner$ If $\mathrm{p}, \mathrm{q}\urcorner$ in the canonical way, then the Y factors must be present for $\mathrm{S}$ with respect to p. Given extra-sensitive invariantism, this entails that in no context does $\ulcorner\mathrm{S}$ knows whether $\mathrm{p}\urcorner$ express a truth. This is surely a cost to the view. (Thanks to an anonymous reviewer for pressing me to address this proposal.) 
contexts of use. Whether a sentence like $\ulcorner\mathrm{S}$ knows whether $\mathrm{p}\urcorner$ expresses a truth in a context of use depends both on the purely epistemic facts concerning S's relation to $\mathrm{p}$ and the interpretation of 'knows' active in that context. It is therefore possible for the truth value of $\ulcorner\mathrm{S}$ knows whether $\mathrm{p}\urcorner$ to change even when none of the epistemic facts concerning S's relation to $\mathrm{p}$ do. And this means the contextualist can accept IGNORANCE (as well as principles like KNA) without reservation: any context in which the $\ulcorner\mathrm{S}$ may assert 'If $\mathrm{p}$, q' in the canonical way ' expresses a truth is a context in which the proposition expressed by $\ulcorner\mathrm{S}$ knows whether $\mathrm{p}\urcorner$ expresses a falsehood. Thus, for the contextualist, the fact there are situations in which 'If Oswald didn't shoot Kennedy, then someone else did' is assertable in the canonical way shows that there are contexts in which, for the relevant $\mathrm{S},\ulcorner\mathrm{S}$ knows whether Oswald shot Kennedy $\urcorner$ expresses a falsehood. Our judgments about the assertability of conspiracy conditionals shift readily for the simple reason that the interpretation of 'knows' shifts readily. ${ }^{39}$

Of course, there remains the question of why 'knows' sometimes undergoes these shifts in interpretation. Why is it that in some circumstances we are inclined to assert 'Oswald shot Kennedy', yet in others we are inclined to assert (in the canonical way) 'If Oswald didn't shoot Kennedy, then someone else did'? This is a question about the meta-semantics underlying the contextualist's semantics for 'knows'. And although we need not have a meta-semantic theory of the mechanisms driving the context-sensitivity of an expression to know that that expression is context-sensitive, it would certainly be nice to have one. ${ }^{40}$ 39 This isn't to say that the story is perfectly tidy. As an anonymous reviewer points out, speeches like the following seem
infelicitous:

(47) ? If Oswald didn't shoot Kennedy, then someone else did. I say this because we don't know whether Oswald shot Kennedy.

Given IGNORANCE and a contextualist theory of 'knows' this is something of a surprise. Supposing the speech occurs in a single context, the first sentence is felicitously assertable (in the canonical way) only if the second sentence is true. So why should it sound bad?

I don't know the answer to this question. But I also don't think it's the epistemic contextualist's job to answer it. The strangeness of (47) seems to be part of a more general pattern. For example: just about every mainstream theory of knowledge should agree that there are situations in which $\ulcorner$ S doesn't know whether it will rain tomorrow $\urcorner$ expresses a truth. Yet to my ears (48) seems just as bad in S's mouth as (47) does:

(48) ? If it will rain tomorrow, then we won't be able to play tennis. I say this because we don't know whether it will rain tomorrow.

Likewise, it's not hard to find contexts in which in asserting a sentence like 'Everyone is here', one expresses the true proposition that everyone in the philosophy department is here. Yet it sounds very strange to say something like:

(49) ? Everyone is here. In fact, everyone is a member of the philosophy department.

But again, in any context in which the first sentence expresses a truth (given the circumstances of the world), the second must express a truth too. My hunch is that whatever explains the badness of speeches like (48) and (49) will also explain the badness of (47), but clearly further investigation is needed.

${ }^{40}$ Ichikawa (2011) makes a similar point in defense of Lewis's (1996) theory of 'knows'. 
Unfortunately, I have little sense of what the correct meta-semantic theory for our judgments about conspiracy conditionals might look like. If the arguments of $\S 7$ give us good reason to reject a stakes- and/or salience-based error theory of our judgments, then they give us equally good reason to reject a stakes- and/or salience-based contextualist meta-semantics for them too. And this makes things awkward for the contextualist, as these happen to be the main kinds of meta-semantics for 'knows' on the market. ${ }^{41}$ Worse, given the unruly nature of the data considered throughout this paper, it is not obvious whether the contextualist can say anything systematic about the conditions in which conspiracy conditionals will be felicitously assertable.

This raises the following worry: if the contextualist doesn't have a theory that tells us why in certain circumstances the interpretation of 'knows' shifts so as to make conspiracy conditionals canonically assertable, then in what sense is the contextualist doing any better than the error-theoretic moderate invariantist in accounting for our intuitive judgments about conspiracy conditionals? ${ }^{42}$ The contextualist has to abandon stakes- and salience-based meta-semantic theories in favor of a meta-semantic black box. And if it's open to the contextualist to do this, then why isn't it equally open to the moderate invariantist to abandon stakes- and salience-based error theories in favor of an error-theoretic black box? Aren't both views equally (un)predictive about our intuitive judgments about conspiracy conditionals?

Although I think this is a natural worry for the contextualist, I also think it ultimately mistakes the dialectical situation. The debate between the contextualist and the moderate invariantist is not a debate about which view better predicts the relevant set of intuitive judgments about knowledge. ${ }^{43}$ In fact, it is hard to see how the debate could possibly be settled by such considerations. This is because there is no prediction one style of view can make that the other style of view cannot. Suppose the contextualist lands on a fully predictive meta-semantics for her contextualist semantics for 'knows'. It tells us exactly when and why 'knows' undergoes shifts in interpretation, whether in the form of a knowledge ascription or in the form of a judgment about the assertability of an indicative conditional. Say these shifts are always due to shifts in mechanism "Z" or something of the sort. Would the contextualist then have a more predictive theory than the moderate invariantist? She would not. For nothing stops the moderate invariantist from rebranding the contextualist's meta-semantics as an error theory. That is: it is entirely open to the moderate invariantist to claim that shifts in the $\mathrm{Z}$ factors do not cause shifts in the interpretation of 'knows'; rather, they cause errors in our judgments about its contextinvariant intension. The two views will be exactly as good at predicting our felicity judgments about knowledge ascriptions and the assertion of conspiracy conditionals. The only difference between them will be in how they categorize these judgments: the contextualist will claim that they are generally responsive to the underlying facts, the moderate invariantist will claim that

${ }^{41}$ For representative examples see, e.g., Heller (1995); Lewis (1996); Cohen (1998); Rieber (1998); Neta (2002); DeRose (2009).

${ }^{42}$ Thanks to an anonymous reviewer for pressing this concern.

${ }^{43}$ Although I exclude the sensitive and skeptical invariantists from the current discussion, similar lessons can be drawn for the four-party debate. 
they are often mistaken. But a difference in categorization is not a difference in predictiveness.

What this suggests is that the debate between the contextualist and the moderate invariantist is about explanation rather than empirical coverage. And on this issue I think things are decidedly not equal: the contextualist's theory does a much better job than the moderate invariantist's in explaining why we think and talk the way we do. The reason why is simple: the contextualist says our intuitive judgments about the assertability of conspiracy conditionals are competent; the moderate invariantist says they are not. And unless we have independent reason to believe that the kinds of psychological factors that correlate with our intuitive judgments about the assertability of conspiracy conditionals tend to produce conceptual errors, we should strongly prefer theories that make us competent users of our concepts to those that do not. This is precisely why moderate invariantists like Williamson (2005) attempt to explain away our intuitions about skeptical knowledge ascriptions using independently attested error producing mechanisms: in Williamson's case, the well established human tendency to overestimate the chances of events that are psychologically salient or of a matter of significant personal interest. Without this kind of constraint-a requirement that the error theory make the existence of the putative errors unsurprising - the error theorist simply does too much violence to basic principles of interpretive charity.

In short then, a semantic theory that posits unexplained errors is ceteris paribus worse than a theory that posits unexplained shifts in context. Indeed, it is precisely because the psychological basis of our intuitive judgments about conspiracy conditionals appears elusive that they provide such strong evidence in favor of contextualist theories of knowledge. And because we know that IGNORANCE is true, that conspiracy conditionals are judged to be assertable in the canonical way, and that these judgments can neither be systematically mistaken nor systematically knowledgedestroying, we know that some version of contextualism about knowledge has to be correct. The rest is a matter of sorting out the details. 


\section{References}

Adams, Ernest W. 1970. Subjunctive and Indicative Conditionals. Foundations of Language, 6(1), 89-94.

Adler, Jonathan E. 2006. Withdrawal and Contextualism. Analysis, 66(4), 280-285.

Austin, J. L. 1946. Other Minds. Supplementary Proceedings of the Aristotelian Society, 20, 149-187.

Bach, Kent. 2005. The Emperor's New 'Knows'. Pages 51-89 of: Preyer, Gerhard, \& Peter, Georg (eds), Contextualism in Philosophy: Knowledge, Meaning, and Truth. Oxford University Press.

Bacon, Andrew. 2014. Giving Your Knowledge Half a Chance. Philosophical Studies, 1-25.

Beddor, Bob. Forthcoming. New Work for Certainty. Philosophers' Imprint, 1-27.

Benton, Matthew A. 2016. Gricean Quality. Noûs, 50(4), 689-703.

Buchak, Lara. 2014. Belief, Credence, and Norms. Philosophical Studies, 169(2), 1-27.

Buckwalter, Wesley, \& Schaffer, Jonathan. 2015. Knowledge, Stakes, and Mistakes. Noûs, 49(2), 201-234.

Cohen, Stewart. 1986. Knowledge and Context. Journal of Philosophy, 83(10), 574-583.

Cohen, Stewart. 1998. Contextualist Solutions to Epistemological Problems: Scepticism, Gettier, and the Lottery. Australasian Journal of Philosophy, 76(2), 289-306.

Cohen, Stewart. 1999. Contextualism, Skepticism, and the Structure of Reasons. Philosophical Perspectives, 13(s13), 57-89.

DeRose, Keith. 1992. Contextualism and Knowledge Attributions. Philosophy and Phenomenological Research, 52(4), 913-929.

DeRose, Keith. 1995. Solving the Skeptical Problem. Philosophical Review, 104(1), 1-52.

DeRose, Keith. 2002. Assertion, Knowledge, and Context. Philosophical Review, 111(2), 167-203.

DeRose, Keith. 2009. The Case for Contextualism: Knowledge, Skepticism, and Context, Vol. 1. OUP Oxford.

DeRose, Keith, \& Grandy, Richard E. 1999. Conditional Assertions and "Biscuit" Conditionals. Noûs, 33(3), 405-420.

Dorr, Cian, \& Hawthorne, John. 2013. Embedding Epistemic Modals. Mind, 122(488), 867-914.

Dorr, Cian, Goodman, Jeremy, \& Hawthorne, John. 2014. Knowing Against the Odds. Philosophical Studies, 170(2), 277-287.

Dorst, Kevin. 2019a. Abominable KK Failures. Mind, 1-29.

Dorst, Kevin. 2019b. Lockeans Maximize Expected Accuracy. Mind, 128, 175-211.

Fantl, Jeremy, \& McGrath, Matthew. 2002. Evidence, Pragmatics, and Justification. Philosophical Review, 111(1), 67-94.

Fantl, Jeremy, \& McGrath, Matthew. 2009. Knowledge in an Uncertain World. Oxford University Press.

Gazdar, Gerald. 1979. Pragmatics: Implicature, Presupposition and Logical Form. New York: Academic Press.

Gillies, Anthony. 2010. Iffiness. Semantics and Pragmatics, 3(4), 1-42. 
Gillies, Anthony S. 2004. Epistemic Conditionals and Conditional Epistemics. Noûs, 38(4), 585-616.

Greco, Daniel. 2015. How I Learned to Stop Worrying and Love Probability 1. Philosophical Perspectives, 29(1), 179-201.

Greenough, Patrick, \& Kindermann, Dirk. 2017. The Semantic Error Problem for Epistemic Contextualism. Pages 305-320 of: Ichikawa, Jonathan (ed), Routledge Handbook of Epistemic Contextualism. Routledge.

Grice, H. Paul. 1975. Logic and Conversation. Page 47 of: Ezcurdia, Maite, \& Stainton, Robert J. (eds), The Semantics-Pragmatics Boundary in Philosophy. Broadview Press.

Hawthorne, John. 2004. Knowledge and Lotteries. Oxford University Press.

Hawthorne, John, Rothschild, Daniel, \& Spectre, Levi. 2016. Belief is Weak. Philosophical Studies, 173(5), 1393-1404.

Heller, Mark. 1995. The Simple Solution to the Problem of Generality. Noûs, 29(4), 501-515.

Hintikka, Jaakko. 1962. Knowledge and Belief. Ithaca: Cornell University Press.

Ichikawa, Jonathan. 2011. Quantifiers and Epistemic Contextualism. Philosophical Studies, 155(3), 383398.

Khoo, Justin. 2015. On Indicative And Subjunctive Conditionals. Philosophers' Imprint, 15.

Kim, Brian. 2017. Pragmatic Encroachment in Epistemology. Philosophy Compass, 12(5), e12415.

King, Jeffrey C., \& Lewis, Karen S. 2017. Anaphora. In: Zalta, Edward N. (ed), The Stanford Encyclopedia of Philosophy, summer 2017 edn. Metaphysics Research Lab, Stanford University.

Leahy, Brian. 2011. Presuppositions and Antipresuppositions in Conditionals. Proceedings of Semantics and Linguistic Theory, 257-274.

Lewis, David. 1996. Elusive Knowledge. Australasian Journal of Philosophy, 74(4), 549-567.

May, Joshua, Sinnott-Armstrong, Walter, Hull, Jay G., \& Zimmerman, Aaron. 2010. Practical Interests, Relevant Alternatives, and Knowledge Attributions: An Empirical Study. Review of Philosophy and Psychology, 1(2), 265-273.

McGrath, Matthew. 2007. On Pragmatic Encroachment in Epistemology. Philosophy and Phenomenological Research, 75(3), 558-589.

Nagel, Jennifer. 2008. Knowledge Ascriptions and the Psychological Consequences of Changing Stakes. Australasian Journal of Philosophy, 86(2), 279-294.

Nagel, Jennifer. 2010a. Epistemic Anxiety and Adaptive Invariantism. Philosophical Perspectives, 24(1), 407-435.

Nagel, Jennifer. 2010b. Knowledge Ascriptions and the Psychological Consequences of Thinking About Error. Philosophical Quarterly, 60(239), 286-306.

Neta, Ram. 2002. S Knows That P. Noûs, 36(4), 663-681.

Predelli, Stefano. 2009. Towards a Semantics for Biscuit Conditionals. Philosophical Studies, 142(3), 293305.

Radford, Colin. 1966. Knowledge-By Examples. Analysis, 27(1), 1-11.

Reed, Baron. 2010. A Defense of Stable Invariantism. Noûs, 44(2), 224-244. 
Rieber, Steven. 1998. Skepticism and Contrastive Explanation. Noûs, 32(2), 189-204.

Roeber, Blake. 2018. The Pragmatic Encroachment Debate. Noûs, 171-195.

Rothschild, Daniel. 2019. What It Takes to Believe. Philosophical Studies, 1-19.

Rysiew, Patrick. 2001. The Context-Sensitivity of Knowledge Attributions. Noûs, 35(4), 477-514.

Schaffer, Jonathan. 2005a. The Irrelevance of the Subject: Against Subject-Sensitive Invariantism. Philosophical Studies, 127(1), 87-107.

Schaffer, Jonathan. 2005b. What Shifts? : Thresholds, Standards, or Alternatives? In: Preyer, Gerhard, \& Peter, Georg (eds), Contextualism in Philosophy: Knowledge, Meaning, and Truth. Oxford University Press.

Schaffer, Jonathan. 2007. Knowing the Answer. Philosophy and Phenomenological Research, 75(2), 383403.

Schaffer, Jonathan, \& Szabo, Zoltan Gendler. 2013. Epistemic Comparativism: A Contextualist Semantics for Knowledge Ascriptions. Philosophical Studies, 1-53.

Schiffer, Stephen. 1996. Contextualist Solutions to Scepticism. Proceedings of the Aristotelian Society, 96(1), 317-333.

Stalnaker, Robert. 1975. Indicative Conditionals. Philosophia, 5(3), 269-286.

Stalnaker, Robert. 1984. Inquiry. Cambridge University Press.

Stalnaker, Robert. 1999. Context and Content: Essays on Intentionality in Speech and Thought. Oxford University Press UK.

Stalnaker, Robert. 2002. Common Ground. Linguistics and Philosophy, 25(5-6), 701-721.

Stanley, Jason. 2005. Knowledge and Practical Interests. Oxford University Press.

Stanley, Jason. 2008. Knowledge and Certainty. Philosophical Issues, 18(1), 35-57.

Turri, John. 2016. Knowledge and the Norm of Assertion: An Essay in Philosophical Science. Cambridge: Open Book Publishers.

Unger, Peter K. 1975. Ignorance: A Case for Scepticism. Oxford University Press.

von Fintel, Kai. 1999. The Presupposition of Subjunctive Conditionals. Pages 29-44 of: Sauerland, Uli, \& Percus, Orin (eds), The Interpretive Tract. MIT Working Papers in Linguistics 25.

Weatherson, Brian. 2012. Knowledge, Bets, and Interests. Pages 75-103 of: Brown, Jessica, \& Gerken, Mikkel (eds), Knowledge Ascriptions. Oxford University Press.

Williamson, Timothy. 2000. Knowledge and its Limits. Oxford University Press.

Williamson, Timothy. 2005. Contextualism, Subject-Sensitive Invariantism and Knowledge of Knowledge. The Philosophical Quarterly, 55(219), 213-235.

Worsnip, Alex. 2017. Contextualism and Knowledge Norms. In: Ichikawa, Jonathan (ed), The Routledge Handbook of Epistemic Contextualism. Routledge. 